\title{
ELEMENTARY REACTIONS IN POLYNUCLEAR IONS AND AQUEOUS-MINERAL INTERFACES: A NEW GEOLOGY
}

\author{
JAMES R. RUSTAD \\ Department of Geology, University of California, One Shields Ave, Davis, \\ CA 95616, USA
}

I. Molecular Geology

II. Modeling Tools for Geochemical Systems 393

A. Potential Energy Functions 394

B. Obtaining Model Parameters 398

$\begin{array}{ll}\text { III. Example Systems } & 402\end{array}$

A. Broensted Acid-Base Reactions 402

B. Water, Hydroxide, and Oxide Exchange Kinetics 416

C. Polyoxoanions 423

IV. Geological Problems with Molecular Level Solutions 428

A. Boron Isotopes in Marine Minerals 428

B. Carbon Isotopes In Soil Minerals 430

C. Final Remarks 433

References 433

\section{Molecular Geology}

Since they first puzzled over the geometric regularity of faceted crystals, geologists have been striving for a molecular-level understanding of the processes that control the transformation of earth materials. The relative lack of success in this endeavor can be revealed by asking why, if everyone knows what a "molecular biologist" is, there is no such corresponding occupation as a "molecular geologist." That this should be so is even more surprising considering the vast amount of effort devoted over the 20th century to the determination of thousands of crystal structures of minerals of geological importance. Up through the 1970s every geology department in a major research university had at least 
one specialist in X-ray mineralogy and crystallography. Roughly contemporaneous with the understanding of plate tectonics, geology had completed a remarkably comprehensive database of the crystal structures of thousands of minerals making up the Earth's crust and the more remote mineral assemblages making up the Earth's mantle. Uncovering the fundamental atomic structures of earth materials should have had the same transformational effect on geology that, for example, protein crystallography had on biology. The most basic and most interesting questions, such as the motions of tectonic plates, the rates of dissolution and weathering of rocks at the earth's surface into primary oxides and clay minerals, the process of replacing and preserving biological materials with minerals on deep time-scales, and the fractionation of isotopes during establishment of the earth's rock record have a molecular component that is no less central or less fascinating than those underpinning biological processes.

Many of these questions are not purely academic. For example, it is well known that ice bubbles trapped in ice sheets such as the one covering Greenland and Antarctica can be used to reconstruct the composition of earth's atmosphere over the past 750,000 years (1). Because atmospheric $\mathrm{CO}_{2}$ levels have never exceeded 300 ppm during that time, society is now concerned with the 380 ppm $\mathrm{CO}_{2}$ levels found in the atmosphere today. However, a million years is a relatively short time scale for geological processes. There are techniques that can probe, indirectly using carbon and boron isotopes, atmospheric $\mathrm{CO}_{2}$ concentrations on much longer 10-100 million-year timescales and indicate that $\mathrm{PCO}_{2}$ levels may have been 10-15 times higher over a significant fraction of the past 650 million years of earth history during which complex life has evolved (2). Effective use of such methods depends on increasingly detailed molecular-level knowledge of how the carbon and boron isotope signatures are imprinted in minerals.

Beginning with a pioneering paper by Gibbs (3), computational chemistry and computational mineral physics have been used extensively in the geosciences. Computational chemistry is much more central to molecular-level geology than it is in molecular biology. Of course, computational chemistry has made important contributions to molecular biology, but molecular biology could, and did, evolve without the field of computational chemistry. It is not clear that this is the case in molecular geology, where the entire context of a molecular-level understanding is often based on computational models of processes that are thought to occur at mineral-water interfaces, grain boundaries, or dislocation cores. Partly this is because 
molecular geology evolved somewhat later than molecular biology, and happened to coincide with the rise of computational chemistry in the 1970s and 1980s. More importantly, the central role of computational chemistry in the earth sciences arises because molecular-level characterization of interfaces, where much of the action takes place in geological phenomena, is a more difficult problem than determination of the molecular structure of, for example, proteins. Obviously, both proteins and minerals can be crystallized. In fact, one of the earliest studies in protein crystallography was a collaborative effort between a physiologist and a mineralogist, resulting in a remarkable collection of hemoglobin crystals collected from hundreds of different species (4). That a physiologist should seek aid from a mineralogist in searching for a more fundamental molecular understanding of biological processes seems ironic now, and pointedly highlights the divergence of research directions in each of these fields since that time.

Because mineral transformations are often governed by surface phenomena, geologists are only now beginning to resolve surface structures at a sufficiently fine scale to think about potential molecular-level processes. When structural details are resolved, after great effort, it is often difficult to connect this detail to any mechanistic understanding of a geological process, because only a static picture of the process is achieved. Part of the reason for the difference in focus on molecular processes in geology and biology may reflect the fact that because the whole point of protein structure is function, the structures are often much more directly suggestive of function. For proteins and nucleic acids, the need computational chemistry to guide the connection between structure and function may not be as crucial as it is for earth materials. Furthermore, geological processes often operate on much longer timescales than those that are of interest to biology, ultimately meaning that the long-term evolution of geological micro or nano structure could depend on small structural details whose consequences only become apparent on long time scales. Progress in understanding earth materials at a molecular level is strongly dependent on advances in computational chemistry.

\section{Modeling Tools for Geochemical Systems}

While there is a long history of using parameterized force fields to study minerals (5), molecular modeling of reactive processes, involving coupled ligand, proton, and electron-exchange reactions 
in aqueous media requires flexible capabilities. Since Car and Parrinello's paper in 1985 (6), there has been rapid progress in direct dynamics with forces calculated from electronic structure calculations, but these techniques are still computationally too expensive for routine modeling tasks on polynuclear ions and surfaces. Progress on practical research problems in geochemistry is much faster if there is a parameterized model with sufficient flexibility to simulate these coupled processes at a reasonably accurate level. By "conventional" molecular dynamics (MD) it is meant that the interatomic interactions can be expressed as distances, angles, torsions, etc., between pairs, triplets, quadruplets, etc., of atoms. Many, or even most, definitive, quantitative calculations will still require electronic structure calculations; however, design of expensive "ab initio" numerical experiments can be much more effective if there exists a molecular modeling capability for large systems and, maybe even more important, rapid simulations for small systems, which can be completed on time-scales that are nearly interactive.

For interfacial systems, potential functions should ideally be transferrable from the gas-phase to the condensed phase. Aqueous-mineral interfaces are not in the gas phase (although they may be close, see (7)), but both the water molecules and the atoms/ions in the substrate are in contact with an environment that is very different from their bulk environment. The easiest "different environment" to test, especially when comparing with electronic structure calculations, is a vacuum, so there is likely to be a great deal of information available on either the surface of the solid or the gas-phase polynuclear ion or the gas-phase aquo complex (i.e., $\mathrm{Fe}\left(\mathrm{H}_{2} \mathrm{O}\right)_{6}{ }^{3+}, \mathrm{CO}_{3}\left(\mathrm{H}_{2} \mathrm{O}\right)_{6}{ }^{2-}$ ). The gas-phase transferability requirements on potential functions are challenging, but it is difficult to imagine constructing "effective" potential functions for such systems without using gas-phase systems in the construction process. This means that any water molecules used on these complexes must also "transfer" from the gas phase to the condensed phase. A fundamental aspect of this transferability is polarization.

\section{A. Potential Energy Functions}

The potential model for water used in our work is taken from the work of Stillinger and David (8) (SD) as modified by Halley and co-workers (9) (HRR). Models for water that are capable of heterolytic dissociation into ions $\mathrm{OH}^{-}$and $\mathrm{H}^{+}$could take two different approaches. Probably the best approach, promising but not yet 
broadly applied to aqueous systems, is to assign environmentdependent charges governed by the principle of electronegativity equalization (10). An earlier approach, the one taken by Stillinger and David, is to treat the water molecule as having formal +1 and -2 point charges on the proton and oxide ions, respectively, essentially creating an ionic model for water of the type that is used to model molten salts and oxide minerals (11). The oxide ion is polarizable, and, unlike many polarizable water models, the dipole moment of the oxide ion responds to the electric field of the protons within the molecule. If the oxide ion is assigned a polarizability of $1.444 \AA^{3}$ and experiences the full-charge dipole interaction of a +1 proton at $1 \AA$, the induced dipole moment will be too large, and the overall moment too small, compared to the known dipole moment of a gas-phase water molecule $(1.85 \mathrm{D})$. Stillinger and David therefore introduced a smooth cutoff function, which multiplies the charge-dipole interaction and reduces it at short range. The parameters are chosen such that the gas-phase dipole moment is exactly $1.85 \mathrm{D}$. Halley and co-workers implemented a short-ranged angle-dependent potential to recover the gas-phase vibrational frequencies for the isolated water molecule. The potential expressions are given as follows:

$$
\begin{aligned}
\Phi_{O O}\left(r_{O O^{\prime}}, \vec{\mu}_{O}, \vec{\mu}_{O^{\prime}}\right)= & \frac{1}{2} \sum_{O} \sum_{O} \frac{A_{O O}}{r_{O O}^{\prime 12}}+\frac{B_{O O}}{r_{O O}^{\prime 6}}+\frac{q_{O} q_{O}^{\prime}}{\mathrm{r}_{O O}^{\prime}}+\frac{q_{O}(\vec{\mu} \cdot \vec{r})}{r_{O O}^{\prime 3}} \\
& +\frac{1}{2} \vec{\mu}_{O}\left(\overleftrightarrow{I}-\frac{3 \vec{r}_{O O^{\prime}} \vec{r}_{O O^{\prime}}}{r_{O O^{\prime}}^{2}}\right) \vec{\mu}_{O}^{\prime}
\end{aligned}
$$

where $\vec{r}_{i j}=\vec{r}_{i}-\vec{r}_{j}, \overleftrightarrow{I}$ is the $3 \times 3$ unit matrix, and $\vec{\mu}_{0}$ is the dipole vector on the oxygen. The functional form of the $\mathrm{O}-\mathrm{H}$ interaction is

$$
\begin{aligned}
\Phi_{O H}\left(r_{O H}, \vec{\mu}_{O}\right)= & \sum_{O} \sum_{H} a_{O H} \frac{e^{-b_{O H} r_{O H}}}{r_{O H}} \\
& \left.+\left\{c_{O H}\left(r_{O H}-r_{0_{O H}}\right)^{2}-d_{O H}\left(r_{O H}-r_{O_{O H}}\right)\right\} e^{-e_{O H}\left(r-r_{O H}\right.}\right) \\
& +\frac{q_{O} q_{H}}{r_{O H}}+\frac{q_{H}\left(\vec{\mu}_{O} \cdot \vec{r}_{O H}\right)}{r_{O H}^{3}} S_{O H}
\end{aligned}
$$

where

$$
S(r)=\frac{r^{3}}{r^{3}+f(r)}
$$


and

$$
f(r)=\frac{f_{O H}\left(r-r_{0_{O H}}\right) e^{-g_{O H}\left(r-r_{0 H}\right)}+h_{O H} e^{-p_{O H} r}}{1+e^{S_{O H}\left(r-t_{O H}\right)}}
$$

$\mathrm{H}-\mathrm{H}$ interactions are purely coulombic

$$
\Phi_{H H}\left(r_{H H}^{\prime}\right)=\frac{1}{2} \sum_{H} \sum_{H}^{\prime} \frac{q_{H} q_{H}^{\prime}}{r_{H H}^{\prime}}
$$

For water molecules, there is a three-body term of the form

$$
\begin{aligned}
\Phi_{\mathrm{HOH}}\left(r_{\mathrm{OH}}, r_{\mathrm{OH}}, \theta_{\mathrm{HOH}}\right) \sum_{O} \sum_{H} \sum_{H^{\prime}}\left\{\phi\left(r_{\mathrm{OH}}, r_{O H^{\prime}}, \theta_{\mathrm{HOH}}\right)\right\} \\
\times \exp \left(-e_{\mathrm{HOH}}\left[\left(r-r_{0_{O H}}\right)^{2+}\left(r-r_{0_{O H}}\right)^{2}\right]\right) \\
\phi\left(r, r^{\prime}, \theta\right)=a_{H O H}\left(r-r_{0_{O H}}\right)\left(r^{\prime}-r_{0_{O H}}\right)+\frac{1}{2} b_{H O H}\left(\theta-\theta_{0}\right) \\
+c_{H O H}\left(r+r^{\prime}-2 r_{0_{O H}}\right)\left(\theta-\theta_{0}\right)+d_{H O H}\left(\theta-\theta_{0}\right)
\end{aligned}
$$

where $r_{0_{O H}}$ and $\theta_{0}$ are the desired bond length and bond angle in the water molecule. These parameters are chosen such that the isolated water molecule has the correct vibrational frequencies.

\section{TABLE I}

Potential Parameters for Water Model

\begin{tabular}{llll}
\hline $\mathrm{A}_{\mathrm{OO}}$ & 2.02 & $\mathrm{a}_{\mathrm{HOH}}$ & -0.640442 \\
$\mathrm{~B}_{\mathrm{OO}}$ & 1.35 & $\begin{array}{l}\mathrm{b}_{\mathrm{HOH}} \\
\mathrm{c}_{\mathrm{HOH}}\end{array}$ & -0.347908 \\
& & $\mathrm{~d}_{\mathrm{HOH}}$ & -0.021625 \\
$\mathrm{a}_{\mathrm{OH}}$ & 10.173975 & $\mathrm{e}_{\mathrm{HOH}}$ & 16.0 \\
$\mathrm{~b}_{\mathrm{OH}}$ & 3.69939 & $\theta_{0}$ & 104.45 \\
$\mathrm{c}_{\mathrm{OH}}$ & -0.473492 & & \\
$\mathrm{~d}_{\mathrm{OH}}$ & 0.088003 & $\mathrm{q}_{\mathrm{H}}$ & $1+$ \\
$\mathrm{e}_{\mathrm{OH}}$ & 16.0 & $\mathrm{q}_{\mathrm{O}}$ & $2-$ \\
$\mathrm{f}_{\mathrm{OH}}$ & 1.3856 & $\alpha$ & $1.444 \AA^{3}$ \\
$\mathrm{~g}_{\mathrm{OH}}$ & 0.01 & & \\
$\mathrm{~h}_{\mathrm{OH}}$ & 48.1699 & & \\
$\mathrm{p}_{\mathrm{OH}}$ & 3.79228 & & \\
$\mathrm{~s}_{\mathrm{OH}}$ & 3.0 & & \\
$\mathrm{t}_{\mathrm{OH}}$ & 5.0 & & \\
$\mathrm{r}_{0}$ & 0.9584 & & \\
\hline
\end{tabular}

When used in conjunction with Equations (1 through 6), energies in $\mathrm{e}^{2} / \AA$ are generated. For reference, the water molecule at equilibrium geometry has an energy of $3.11595 \mathrm{e}^{2} / \AA$ 
Table I lists the potential parameters in units of e (charge), $\AA$ (length), and $\mathrm{e}^{2} / \AA$ (energy).

In the HRR model, $\mathrm{O}-\mathrm{O}$ interactions were chosen to reproduce as closely as possible the $\mathrm{O}-\mathrm{O}$ radial distribution function (12), the oxygen-oxygen distance in the water dimer, and the water dimer binding energy. For the HRR model, the ambient pressure at room temperature is about $0.7 \mathrm{GPa}$. It can be adjusted to zero pressure by changing the $\mathrm{B}_{\mathrm{OO}}$ coefficient to -1.35 ; however, the dimer binding energy is then too high $(11.7 \mathrm{kcal} / \mathrm{mol})$ and the $\mathrm{O}-\mathrm{O}$ distance in the water dimer is then too close $(2.75 \AA)$. This is, in a sense, the price that must be paid for insisting on gas-phase to condensedphase transferability. The average water dipole moment at $300 \mathrm{~K}$ in pure water is close to 3.0 debye, in good agreement with estimates from density functional methods (13); thus the model passes probably the most important test of gas-phase to liquid-phase transferability. The proton in water yields a mixture of Eigen and Zundel $\mathrm{H}_{5} \mathrm{O}_{2}{ }^{+}$structures, whereas the hydroxide ion yields a subequal mixture of $\mathrm{OH}\left(\mathrm{H}_{2} \mathrm{O}\right)_{3}{ }^{-}$and $\mathrm{OH}\left(\mathrm{H}_{2} \mathrm{O}\right)_{4}{ }^{-}$species (14).

The next step was to extend the model, keeping the same oxide ion as used in the water, but adding other cations beyond $\mathrm{H}^{+}$. The goal was to find a sufficiently flexible metal-oxygen interaction function for the potential to describe both the aquo ion in aqueous solution and the bulk metal oxide structure as accurately as possible. Following (15), the first extension was to iron oxide fitted to quantum mechanical calculations on the $\mathrm{Fe}^{3+}-\mathrm{H}_{2} \mathrm{O}$ potential surface. The functional form allows for polarization of bound water molecules by the $\mathrm{M}^{3+}$ ion. This polarization opposes the contribution of the protons to the induced dipole moment of bound water molecules. The total dipole moments of the bound water molecules are thus larger than that of unbound water molecules. In (15) it was shown that the enhanced (repulsive) dipole-dipole interaction among bound water molecules is an important many-body effect in stabilizing octahedral coordination for $\mathrm{Fe}^{3+}(\mathrm{aq})$. The functional form of the $\mathrm{M}-\mathrm{O}$ interaction is

$$
\begin{aligned}
\Phi_{\mathrm{FeO}}\left(r_{\mathrm{FeO}}, \vec{\mu}_{\mathrm{O}}\right)= & \sum_{\mathrm{Fe}} \sum_{O} A_{\mathrm{FeO}} e^{-B_{\mathrm{FeO}} r_{\mathrm{FeO}}}-\frac{C_{\mathrm{FeO}}}{r_{\mathrm{FeO}}^{6}}+\frac{D_{\mathrm{FeO}}}{r_{\mathrm{FeO}}^{12}}+\frac{q_{\mathrm{Fe}} q_{O}}{r_{\mathrm{FeO}}} \\
& +\frac{q_{\mathrm{Fe}}\left(\vec{\mu}_{\mathrm{O}} \cdot \vec{r}_{\mathrm{FeO}}\right)}{r_{\mathrm{FeO}}^{3}} S_{\mathrm{Fe} O}\left(r_{\mathrm{FeO}}\right)
\end{aligned}
$$

where

$$
S_{\mathrm{FeO}}(r)=1-\frac{1}{e^{E_{F e O}\left(r-F_{F e O}\right)}+1}
$$


TABLE II

Potential Parameters for Cations

\begin{tabular}{lclllll}
\hline Ions & $\mathrm{A}_{\mathrm{MO}}$ & $\mathrm{B}_{\mathrm{MO}}$ & $\mathrm{C}_{\mathrm{MO}}$ & $\mathrm{D}_{\mathrm{MO}}$ & $\mathrm{E}_{\mathrm{MO}}$ & $\mathrm{F}_{\mathrm{MO}}$ \\
\hline $\mathrm{Fe}(2+/ 3+)$ & 1827.7 & 4.925 & -2.136 & -74.680 & 1 & 1.8 \\
$\mathrm{Na}(+)$ & 450.0 & 3.600 & 17.0 & & 3.2 & 1.9 \\
$\mathrm{C}(4+)$ & 4933.9 & 6.35 & 8.52 & 1.5 & 2.738 & 1.20664 \\
$\mathrm{Si}(4+)$ & 220.0 & 4.17 & & & 4 & 1.4 \\
$\mathrm{P}(5+)$ & 120.0 & 3.75 & & & 4 & 1.35 \\
$\mathrm{Nb}(5+)$ & 638.39 & 3.94 & 1.84 & & 3.63 & 1.78 \\
$\mathrm{~S}(6+)$ & 85 & 3.6 & & & 4 & 1.35 \\
$\mathrm{Cr}(6+, 5+, 4+)$ & 248.05 & 3.678 & & & 1.234 & 1 \\
$\mathrm{Cl}(7+)$ & 85 & 3.6 & & & 4 & 1.35 \\
\hline
\end{tabular}

Parameters for $\mathrm{Fe}$, as well as some other cations discussed below, are given in Table II. The parameters may be applied to either $\mathrm{Fe}^{2+}$ or $\mathrm{Fe}^{3+}$ simply by changing the charge.

\section{B. Obtaining Model Parameters}

It has also been possible to make reasonable models for oxyacids $\mathrm{HClO}_{4}, \mathrm{H}_{2} \mathrm{SO}_{4}, \mathrm{H}_{2} \mathrm{CrO}_{4}, \mathrm{H}_{3} \mathrm{PO}_{4}, \mathrm{H}_{4} \mathrm{SiO}_{4}$, and $\mathrm{H}_{2} \mathrm{CO}_{3}$ by treating these species as having central cations with the full +7 $(\mathrm{Cl}),+6(\mathrm{~S}, \mathrm{Cr}),+5(\mathrm{P})$, and $+4(\mathrm{Si}, \mathrm{C})$ formal charges. Since common reactivity trends for these acids are directly related to the "cation" charge, the relative acidities of the species will be at least qualitatively correct when building the potential functions around an ionic framework. The parameters for these species, along with those for $\mathrm{Fe}^{3+/ 2+}$ and $\mathrm{Na}^{+}$, are given in Table II. For the oxyanions ions, we carry out quantum mechanical calculations for protonated, deprotonated, hydroxylated, and dehydroxylated forms of these ions, and fit the parameters to the structures and energies determined from quantum mechanics. A typical set of test molecules relevant to the carbonate system is shown in Fig. 1.

The "gas-phase" model would then be tested on condensed phases. In the case of the carbonate ion, the parameters can be used to examine the structure of $\mathrm{CO}_{2}(\mathrm{aq}), \mathrm{CO}_{3}{ }^{2-}(\mathrm{aq})$, and $\mathrm{HCO}_{3}$ (aq) as well as the structure of, for example, siderite $\mathrm{FeCO}_{3}$ and nahcolite $\mathrm{Na}\left(\mathrm{HCO}_{3}\right)$. For the aqueous species, the most instructive comparisons are with the results of $a b$ initio molecular dynamics studies of solvated ions, where the radial distribution functions can be used to check the extent of solvation. Fig. 2, for 


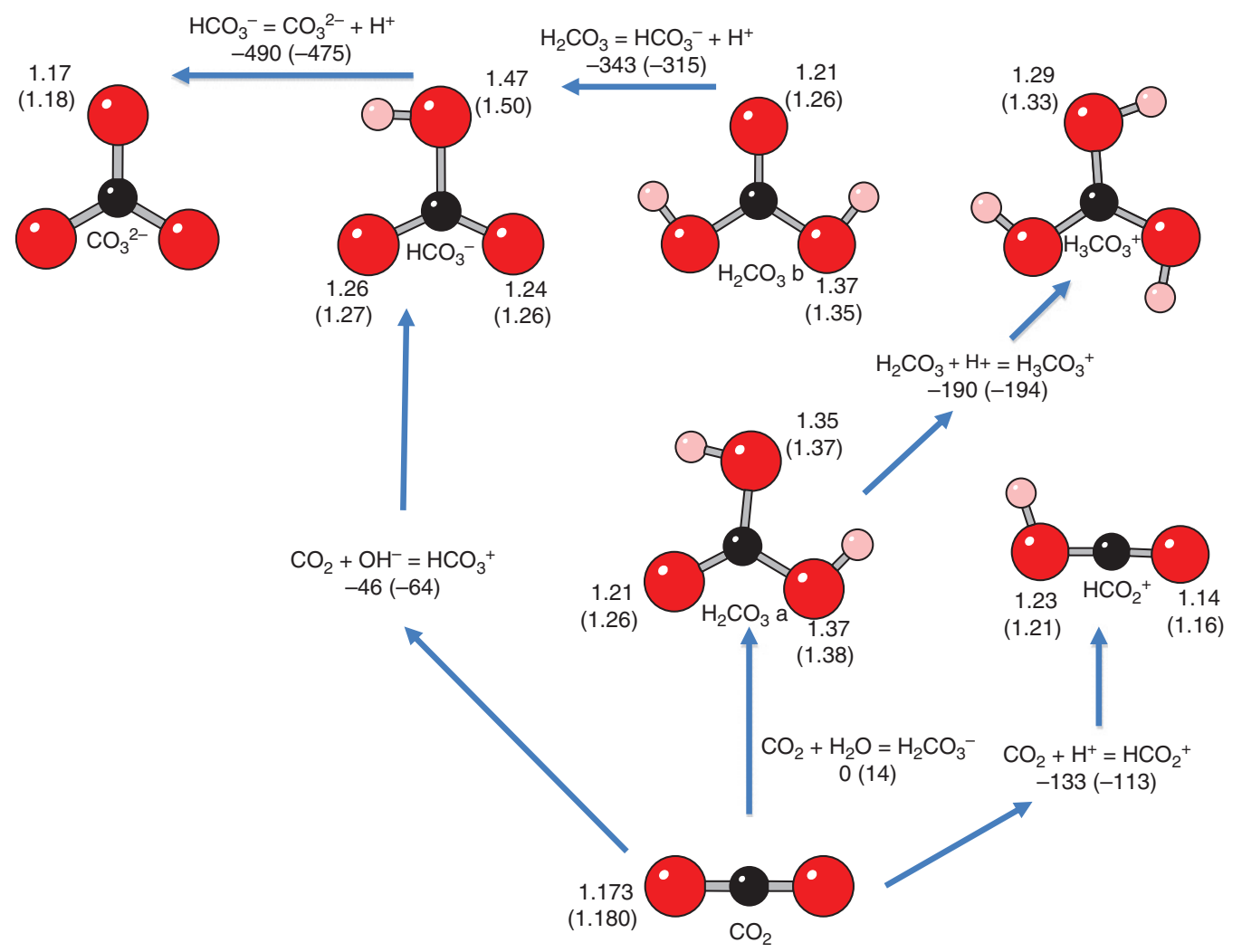

Fig. 1. Molecule training set for fitting potential function parameters for the carbonate system. Red atoms are $\mathrm{O}^{2-}$, black atoms are $\mathrm{C}^{4+}$, and pink atoms are $\mathrm{H}^{+}$. Bond lengths from $\mathrm{C}^{4+}$ to $\mathrm{O}^{2-}$ are given in angstroms. Energies for transformations between the different species are given in $\mathrm{kcal} / \mathrm{mol}$.

example, shows the radial distribution functions obtained with the parameterized model compared with AIMD in the $\mathrm{CO}_{2}$, $\mathrm{HCO}_{3}{ }^{-}, \mathrm{CO}_{3}{ }^{2-}$ systems. It is important to keep in mind the purpose for which the potential function is designed. For example, for the perchlorate ion, the goal may be only to create a large, poorly complexing, highly acidic anion with the appropriate charge. Creating a model for the carbonate ion could be much more challenging, as one needs to account as correctly as possible for the relative energies of multiple protonation states as well as conversion between $\mathrm{CO}_{2}$ and $\mathrm{CO}_{3}{ }^{2-}$ carbon coordination states.

The strategy for fitting parameters can obviously vary from system to system. The task is to produce a model that is capable of describing the wide variety of protonation and coordination states experienced at surfaces and in polynuclear ions. It makes sense to start with structures having coordination environments that may be very different from the regular environments 

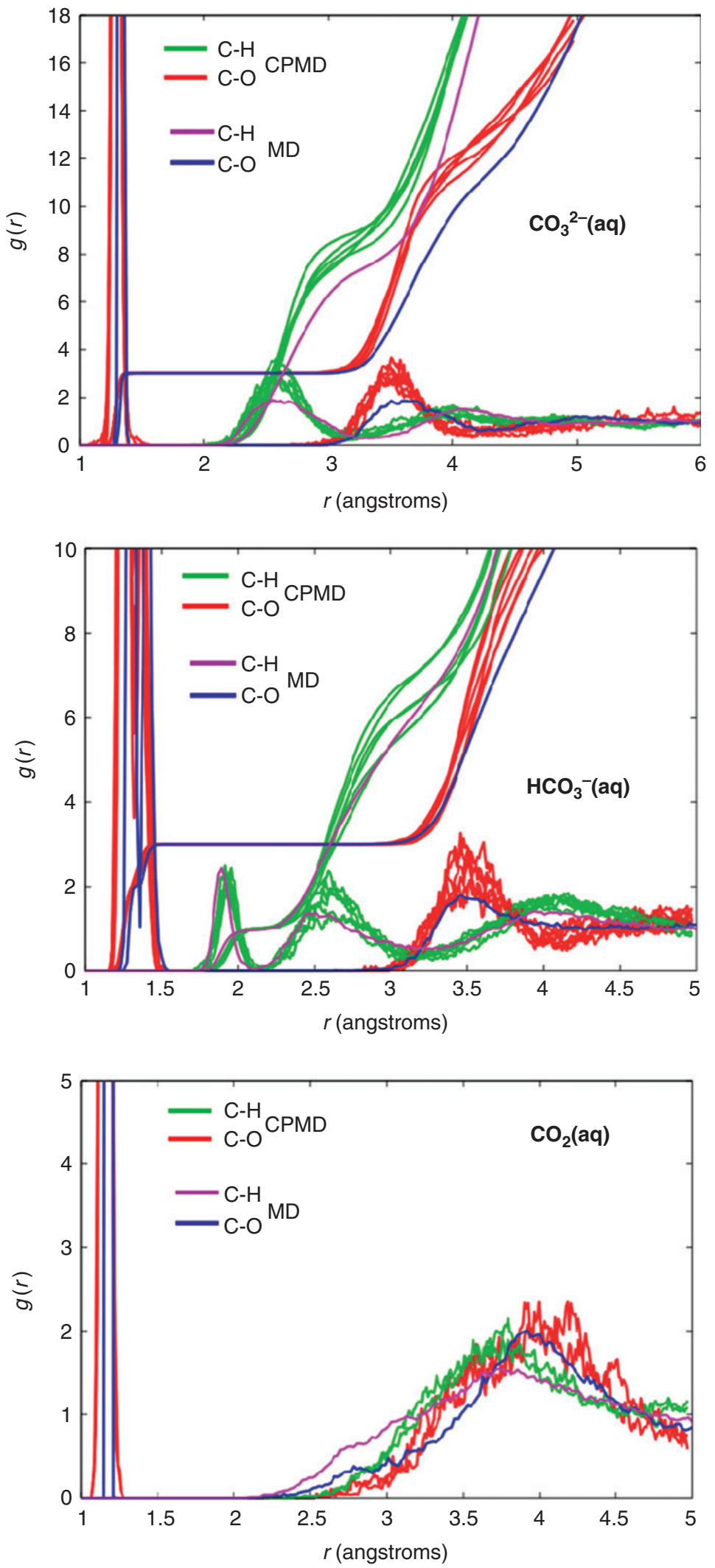

FIG. 2. Radial distribution functions compared between $a b$ initio molecular dynamics (CPMD) and the parameterized molecular dynamics model (MD). Multiple traces for the CPMD calculations represent repeated molecular dynamics calculations. 
experienced in bulk condensed phases, and then checking that these models also give reasonable results for the more regular coordination environments. For this purpose, the structures and energies of quantum mechanical calculations on small molecules provide a manageable, unbiased data set from which to start when fitting the model. Evaluation of model predictions for these quantities is very rapid, so an investigator can get at least a preliminary model in one or two working days.

The choice of the exchange correlation functional in the density functional theory (DFT) calculations is not very important, so long as a reasonable double-zeta basis set is used. In general, the parameterized model will not fit the quantum mechanical calculations well enough for improved DFT calculations to actually produce better-fitted parameters. In other words, the differences between the different DFT functionals will usually be small relative to the errors inherent in the potential model. A robust way to fit parameters is to use the downhill simplex method in the parameter space. Having available an initial set of parameters, taken from an analogous ion, facilities the fitting processes.

As an example application, the fitting of parameters for the $\mathrm{Nb}^{5+}-\mathrm{O}^{2-}$ interaction is described. This model has been used to find potential oxygen exchange pathways in polyoxoniobate anions (16). Fig. 3 shows the molecules used to fit the potential function parameters and gives the model parameters, as well as those calculated using DFT with the BP86 functional and the DZVP basis set. The resulting model is then used to predict the structure of the $\mathrm{Nb}_{10} \mathrm{O}_{28}{ }^{6-}$ ion in solution, shown in Fig. 4, which also provides a comparison between the model bond lengths and bond lengths calculated quantum mechanically in continuum solvent. Other than the terminal oxo bonds being too long, the overall structure of the $\mathrm{Nb}_{10} \mathrm{O}_{28}{ }^{6-}$ (decaniobate) ion is well reproduced by the ionic model.

Even if it is decided that large-scale AIMD or QM/MM studies are required for a particular system (for example, to obtain a more accurate description of the terminal oxo bonds in the decaniobate anion above), the ionic model produced using the above techniques can often serve as a baseline for a better understanding of the more accurate calculations. For example, there is no point in calling on complex rehybridization schemes to "explain" the difference in bond length between the $\mathrm{Nb}_{1}-\mu^{12} \mathrm{O}(1.87 \AA)$ and $\mathrm{Nb}_{2}-\mu^{12} \mathrm{O}(2.12 \AA)$ bonds if these same features can be reproduced with the simple ionic model. If, for example, the "rattling" of the $\mathrm{Nb}^{5+}$ ion in an octahedral oxygen coordination geometry that is slightly too large for the ion is a key aspect of the reaction 


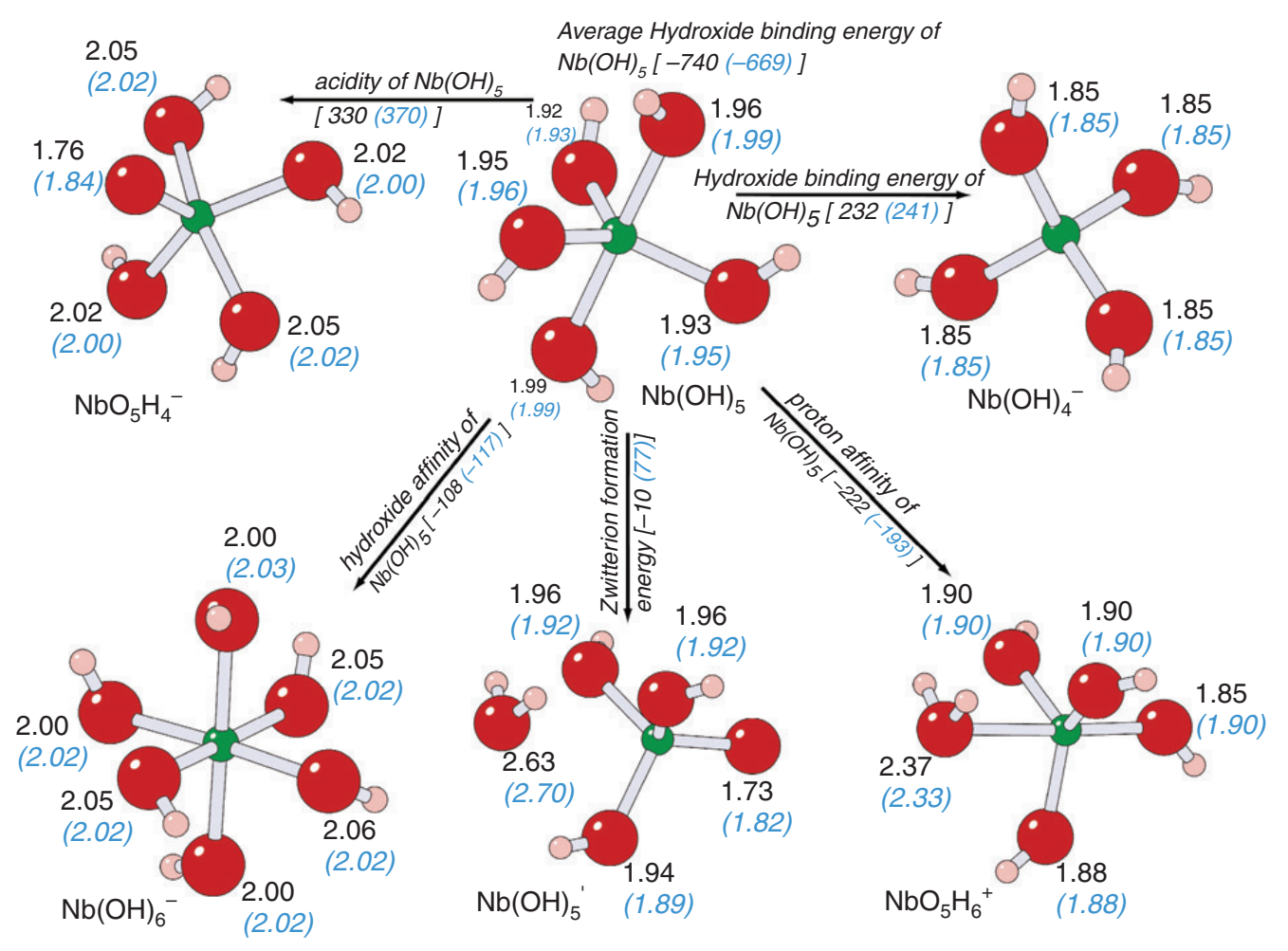

Fig. 3. Molecules used to fit potential parameters for $\mathrm{Nb}^{5+}-\mathrm{O}^{2-}$ interactions. Atoms are as in Figure 1, except that the small green atom is $\mathrm{Nb}^{5+}$. DFT calculations are compared with model predictions. Model predictions are given in parenthesis in blue text. Bond lengths are given in angstroms, and reaction energies are given in $\mathrm{kcal} / \mathrm{mol}$.

pathways for oxygen exchange, the parameterized model, which can account accurately for the relative radius ratios, should be capable of revealing these pathways. Comparing an electronic structure calculation with the simpler model can often make the advantages of the electronic structure approach more immediately apparent.

\section{Example Systems}

\section{A. Broensted Acid-Base Reactions}

\section{A.1. Ion hydrolysis}

Hydrolysis of water molecules induced by ions in aqueous solution or at the surfaces of minerals or polynuclear ions is a fundamental aspect of most dynamic processes taking place at 


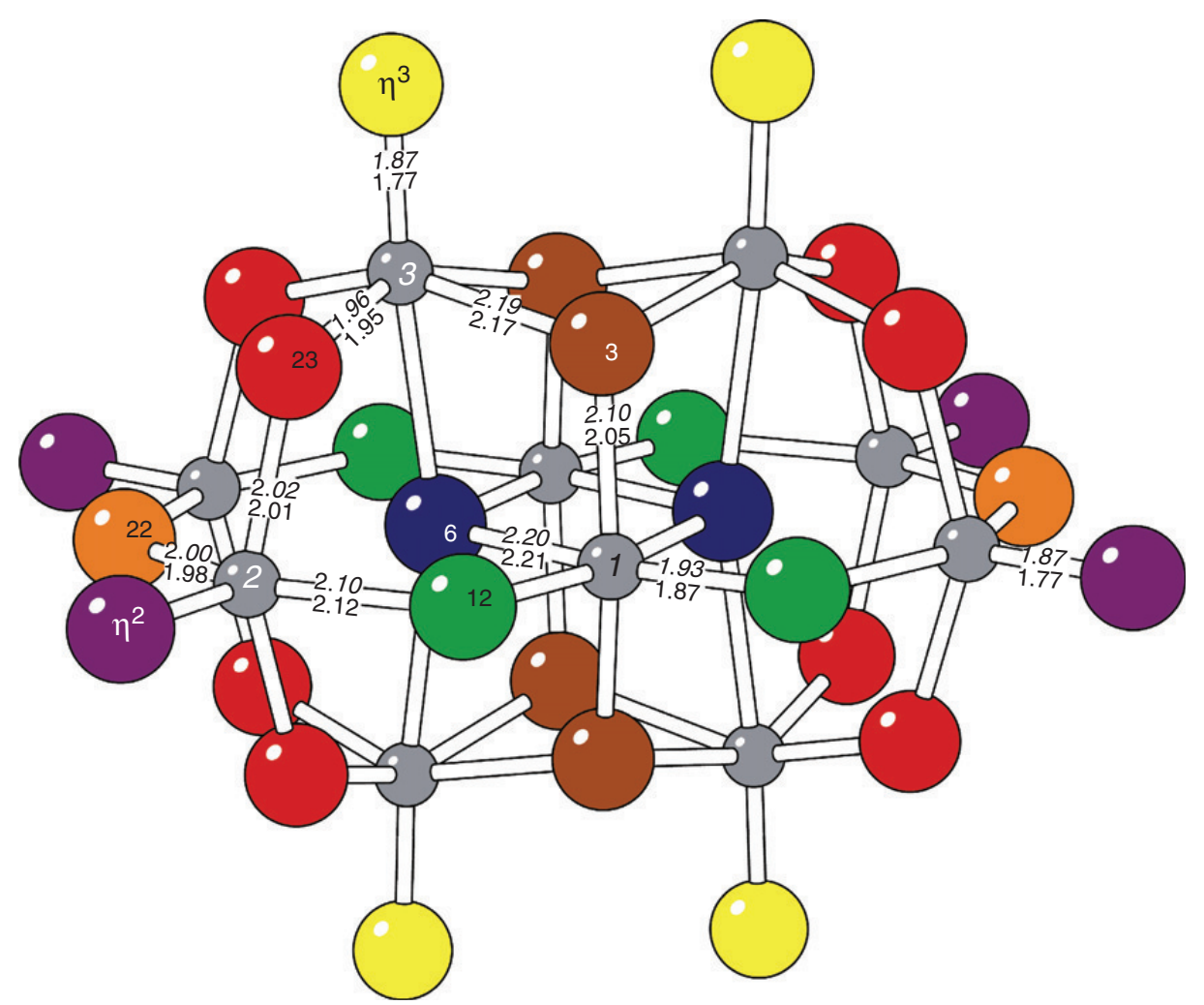

Fig. 4. Decaniobate $\mathrm{Nb}_{10} \mathrm{O}_{28}{ }^{6-}$ ion. Symmetrically equivalent oxygen atoms are shown in different colors. The niobium ions are labeled 1, 2, 3, as shown in the Figure. The oxygen atoms are then labeled with respect to the numbers on the niobium atoms, and whether they are bridging $(\mu)$ or terminal $(\eta)$. Bond lengths are compared for density functional theory in continuum solvent versus model predictions as averaged over a molecular dynamics simulation in water. DFT-calculated bond lengths are above, and model predictions are below, given in angstroms.

oxide-water interfaces. Trivalent cations are often extensively hydrolyzed in aqueous solution according to the reaction:

$$
\mathrm{M}\left(\mathrm{H}_{2} \mathrm{O}\right)_{n}^{3+} \leftrightarrow \mathrm{M}(\mathrm{OH})_{n}^{(3-\mathrm{n})+}+n \mathrm{H}^{+}
$$

In dilute solutions, these reactions produce a series of $\mathrm{M}(\mathrm{OH})_{n}$ $(n=1-4)$ hydrolysis species with populations that depend on solution $\mathrm{pH}$ (17). Hydrolysis chemistry is fundamental to the behavior of trivalent metal ions in water as the extent of hydrolysis governs the polymerization of metal ions into extended structures that eventually crystallize into secondary oxide and oxyhydroxide minerals and clays. When building a general capability to simulation geochemical reaction mechanisms, hydrolysis is the place to begin. If the hydrolysis equilibria of 
the cations are not qualitatively correct, the utility of the molecular model will be extremely limited. Note that in constructing the model, the gas-phase proton affinity of the $\mathrm{M}(\mathrm{OH})^{2+}$ ion can be checked against electronic structure calculations. For example, for the $\mathrm{M}=\mathrm{Fe}^{3+}$ model referenced above, the gas-phase proton affinity is $40 \mathrm{kcal} / \mathrm{mol}$. This is quite a bit higher than the range of values calculated for $\mathrm{Fe}(\mathrm{OH})^{2+}$ from ab initio theory $20-30 \mathrm{kcal} /$ mol $(18,19)$ but very close to the value calculated for $\mathrm{Al}(\mathrm{OH})^{2+}$. The correlation with size-charge ratio for these ions is known to be poor (witness the lesser acidity of the smaller $\mathrm{Al}^{3+}$ ion). Despite the fact that DFT calculations were shown to correlate very well with acidities, the electronic structural reasons for the trends observed in the acidities of the trivalent ions are unclear. Until the underlying reasons for these trends are better understood, the $\mathrm{Al}^{3+}$-like value of $40 \mathrm{kcal} / \mathrm{mol}$ must be accepted, realizing that we are not now really talking about "iron" but a model trivalent ion. Such disagreement may result, from using the same oxygen properties, for example, polarizability, in both the aluminum and iron aquo ions.

In (20) the titration of a model $\mathrm{Fe}^{3+}$ ion in solution was simulated with the $\mathrm{Fe}^{3+}-\mathrm{O}-\mathrm{H}$ MD model described above. Because of the way the model is designed, allowing hydrolysis reactions to occur spontaneously, the distribution of the $\mathrm{M}(\mathrm{OH})_{n}$ species can simply be recorded as a function of the amount of protons and hydroxide ions added to the solution. The simulations are used to find the distribution of hydrolysis species in a neutral solution and to determine how this distribution responds to added protons or hydroxide ions in solution.

To adopt such an approach, there must be a sufficient number of proton exchanges on molecular dynamics timescales for the complexes to provide meaningful averages. Characteristic exchange times for the $\mathrm{Fe}^{3+}$ aquo ion are given in Table III. As expected, there is a strong dependence on the protonation state of the aquo ion. The characteristic time is expected to decrease with increasing $\mathrm{pH}$, as exchange from a hydrolyzed species would be

TABLE III

Characteristic Timescales for Proton Exchange

\begin{tabular}{ll}
\hline Conc. $([\mathrm{H}+]$ or $[\mathrm{OH}-])$ & $\tau$ picoseconds \\
\hline $0.022[\mathrm{H}+]$ & 133 \\
$0.003[\mathrm{H}+]$ & 175 \\
$0.0007[\mathrm{H}+]$ & 106 \\
$0.014[\mathrm{OH}-]$ & 57 \\
\hline
\end{tabular}


expected to be more rapid than from the fully protonated ion. The results show a slight maximum between hydrogen mole fractions $\mathrm{X}_{\mathrm{H}+}=0.022$ and $\mathrm{X}_{\mathrm{H}+}=0.0007$, that is, the rate of proton exchange actually increases with decreasing $\mathrm{pH}$. A similar maximum in proton exchange rate as a function of $\mathrm{pH}$ has been observed in ${ }^{1} \mathrm{H}$ NMR spectroscopy on rhodium(III) in aqueous solutions (21).

The apparent $\mathrm{pH}$ of the neutral solution, in this case $\mathrm{Fe}(\mathrm{OH})_{3}$ in 878 water molecules, can be obtained by taking the observed ratios of the hydrolysis species, for example, for the iron system, the $\mathrm{p} K_{\mathrm{a}}$ for the first hydrolysis reaction

$$
\mathrm{Fe}^{3+}=\mathrm{Fe}(\mathrm{OH})^{2+}+\mathrm{H}^{+}
$$

is 2.2. If, for example, we observe in a solution to which $\mathrm{n}$ protons have been added, that the ratio of $\mathrm{Fe}(\mathrm{OH})^{2+} / \mathrm{Fe}^{3+}$ is nearly unity, then the apparent $\mathrm{pH}$ would be nearly 2.2 .

Each of the $\mathrm{p} K_{1 n}$ pairs can be used to estimate $\mathrm{pH}^{*}$ separately: $\mathrm{p} K_{11}=2.19, \mathrm{p} K_{12}=3.48, \mathrm{p} K_{13}=6.33$, and $\mathrm{p} K_{14}=9.6$. From the observed ratios of each pair of hydrolysis species, $\mathrm{pH}^{*}$ can be defined:

$$
\mathrm{pH}^{*}=\mathrm{p} K_{1 n}+\log \left\{\mathrm{M}(\mathrm{OH})_{n}{ }^{(3-n)} / \mathrm{M}(\mathrm{OH})_{(n-1)}{ }^{(3-n+1)}\right\}
$$

For the neutral systems, over the eight runs, the $\mathrm{pH}^{*}$ estimated from $\mathrm{p} K_{12}$ and the $\log \left[\mathrm{M}(\mathrm{OH})^{2+} / \mathrm{M}(\mathrm{OH})_{2}^{+}\right]$varies from 5.26 to 6.29 (average value $\approx 5.5$ ); $\mathrm{pH}^{*}$ estimated from $\mathrm{p} K_{13}$ and $\log \left[\mathrm{M}(\mathrm{OH})_{2}^{+}\right) /$ $\mathrm{M}(\mathrm{OH})_{3}$ ] ranges from 6.13 to 6.93 (average value $\approx 6.6$ ); and the $\mathrm{pH}^{*}$ estimated from $\mathrm{p} K_{13}$ and $\log \left(\mathrm{M}(\mathrm{OH})_{3}\right) /\left(\mathrm{M}(\mathrm{OH})_{4}^{-}\right)$ranges from 6.5 to 7.6 (average value $\approx 7.1$ ). These ratios should ideally indicate neutral $\mathrm{pH}=7$.

When excess protons or excess hydroxide ions are added to the solution, we expect the ratios of the hydrolysis species to shift to more acidic or basic values. In Fig. 5, we plot the apparent $\mathrm{pH}$ of the solution, as inferred from, on the acid side (where protons are added to the solution), the logarithm of the ratio of the number of counts of the $\mathrm{Fe}(\mathrm{OH})^{2+}$ configurations to the number of counts of the hexaaquo complex, and, on the base side (where hydroxide ions are added to the solution), the logarithm of the ratio of the number of counts for $\mathrm{Fe}(\mathrm{OH})_{4}{ }^{-}$to the number of counts of the $\mathrm{Fe}(\mathrm{OH})_{3}$ complex.

A.2. Effect of hydrolysis on electron-exchange between ferrous and ferric iron in aqueous solution

The capability of the dissociating water model, augmented to include metal-water interactions, to qualitatively describe the process of ion hydrolysis can be applied to the problem of electron 


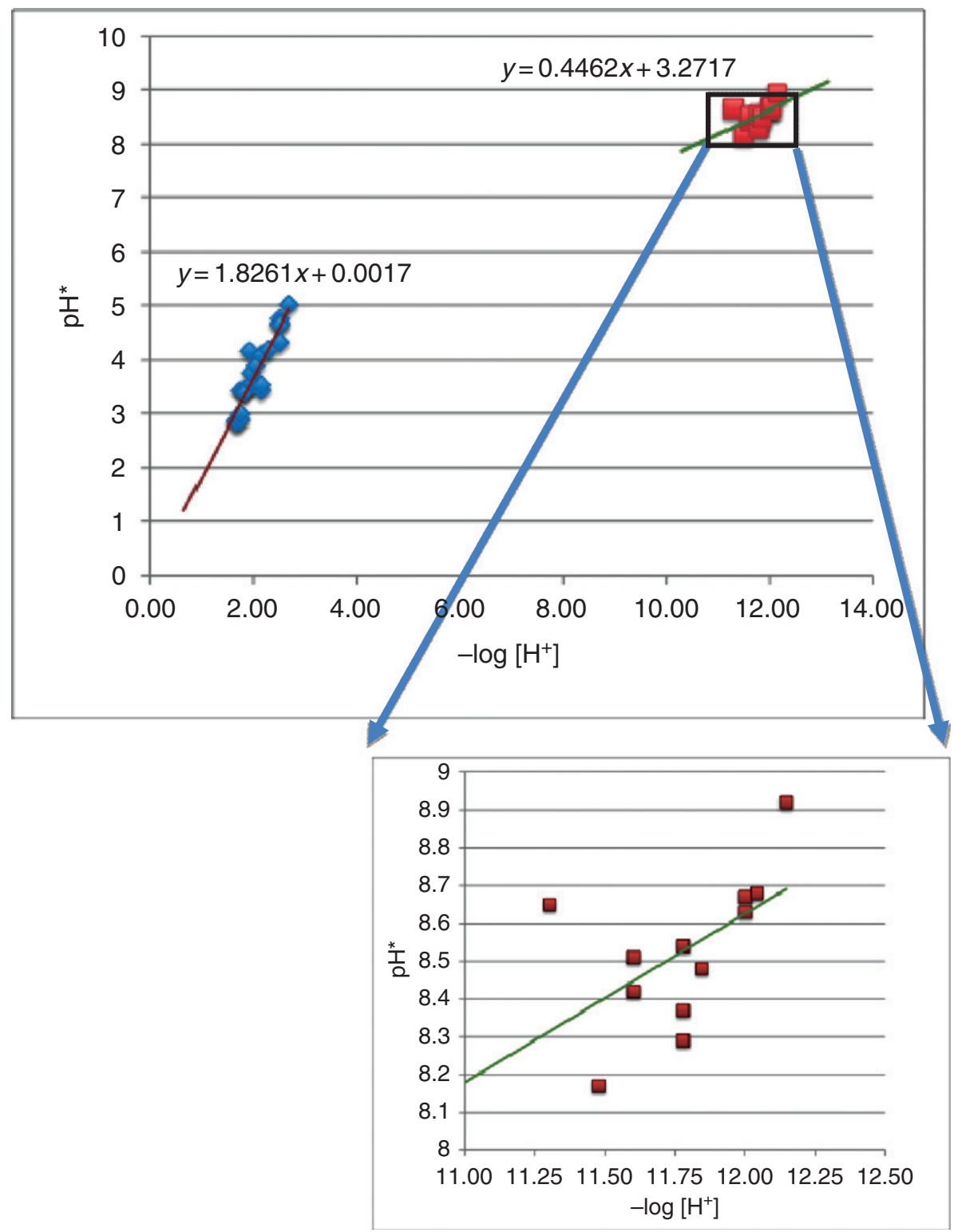

Fig. 5. Apparent $\mathrm{pH}^{*}$ calculated through distributions of $\mathrm{Fe}(\mathrm{OH})^{2+}$ $\mathrm{Fe}^{3+}$ (blue diamonds) and $\mathrm{Fe}(\mathrm{OH})_{4}^{-} / \mathrm{Fe}(\mathrm{OH})_{3}$ (brown squares), versus the $-\log \left[\mathrm{H}^{+}\right]$computed from the number of protons added to the solution on the acid side, or from the amount of added hydroxide, taking $\mathrm{K}_{\mathrm{w}}=14$, on the base side.

transfer between ferrous and ferric iron in aqueous solutions. Early studies showed that self-exchange rates increase by a factor of 4-5 as $\mathrm{pH}$ increased from $0-2$ and the fraction of hydrolyzed ferric iron approaches half of the total ferric iron in solution (22). The hydrolysis of the iron could affect the rate of electron exchange in several ways. First, the reduced charge of the 
$\mathrm{Fe}(\mathrm{OH})^{2+}$ species should lower the potential of mean force between the ferrous and ferric ions. Because it is easier for the ferrous $\mathrm{Fe}^{2+}$ aquo ion to approach the hydrolyzed ferric iron (perhaps even forming an inner-sphere complex), electron exchange between the two species should be facilitated. On the other hand, in the absence of formation of an inner-sphere $\mathrm{Fe}$ (III)-OH-Fe(II) bridge, the presence of hydroxide in the coordination shell of the ferric iron should make it more difficult for the ferric iron to accept an electron because of the increased reorganization energy of the hydrolyzed complex. Finally, the hydrolyzed ferric complex has a more open pathway for accepting a hydrogen atom into the structure, for example, via formation of a $\mathrm{H}_{3} \mathrm{O}_{2}$ bridge that could facilitate a hydrogen atom electron transfer mechanism.

In (23) the importance of the effects of increasing reorganization energies and decreasing potential of mean force with increasing $\mathrm{pH}$ was evaluated using previously developed computational methods $(24,25)$ and the hydrolyzing model for ferric iron described above. A molecular dynamics calculation was carried out for ferrous $\mathrm{Fe}_{\mathrm{A}}{ }^{2+}$ and ferric $\mathrm{Fe}_{\mathrm{B}}{ }^{3+}$ ions in aqueous solution. During the simulation, account is kept of the usual potential energy for the "normal" $\mathrm{Fe}_{\mathrm{A}}{ }^{2+}$ and $\mathrm{Fe}_{\mathrm{B}}{ }^{3+}$ state, as well as the "reversed" $\mathrm{Fe}_{\mathrm{A}}{ }^{3+}$ and $\mathrm{Fe}_{\mathrm{B}}{ }^{2+}$ state. The potential energy difference for a given configuration between the normal and reversed states can be identified with the reorganization energy for electron transfer. On average, the water molecules are more strongly polarized around the ion, so the potential energy of the reversed charge state will be, on average, unfavorable due to the reorganization energy. By keeping track of the probability distribution of reorganization energies, the free energy of electron transfer can be computed. For example, a Gaussian distribution of reorganization energies would correspond to a parabolic free energy surface for electron transfer because the negative logarithm of a Gaussian is a concave-upward parabola. By finding the probability or, equivalently, the free energy for configurations with zero reorganization energy (i.e., zero potential energy difference between the normal and reversed states), the free energy of electron transfer can be estimated.

How would the distribution of hydrolysis species fit into the general picture of solvent fluctuations? Would the reorganization energies, when resolved into contributions from $\mathrm{Fe}^{3+}, \mathrm{FeOH}^{2+}$, $\mathrm{FeOH}_{2}{ }^{+}$, form separate distributions, or would the hydrolysis fluctuations be part of a "continuum" of solvent fluctuations? In other words, is it more correct to regard the phenomenon of hydrolysis, as far as its effect on electron transfer, from the point of view of contributions from separate hydrolysis "species" 
or is it more correct to imagine the process in terms of a continuum of states, but with an increasing overall tendency to "trap" the electron on the ferrous iron as the $[\mathrm{OH}]$ concentration increases, analogous, in a sense, to the effect that would result from increasing the dielectric constant of the solution in which the transfer was taking place?

The results of the calculations, shown in Fig. 6, show widely overlapping reorganization energy distributions for the different hydrolysis species, and strongly support the idea that hydrolysis should more properly be viewed is just another kind of solvent fluctuation on a continuum of types of solvent fluctuations. In other words, there are many $\mathrm{Fe}^{3+}$ configurations having reorganization energies exceeding those of, for example, $\mathrm{Fe}(\mathrm{OH})_{2}^{+}$; in fact, it is not easy to see any difference at all in the average reorganization energies of each hydrolysis species. In terms of the overall effect of $\mathrm{pH}$ on the self-exchange rate, the reduction of the potential of mean force with increasing $\mathrm{pH}$ was balanced by the increased reorganization energy due to hydroxide-induced stabilization of the $\mathrm{Fe}^{3+}$ ion. If the reduction of the potential of mean force exceeds the increase in the reorganization energy, the self-exchange rate would increase with increasing $\mathrm{pH}$. This view contrasted with the existing view that the observed increase in

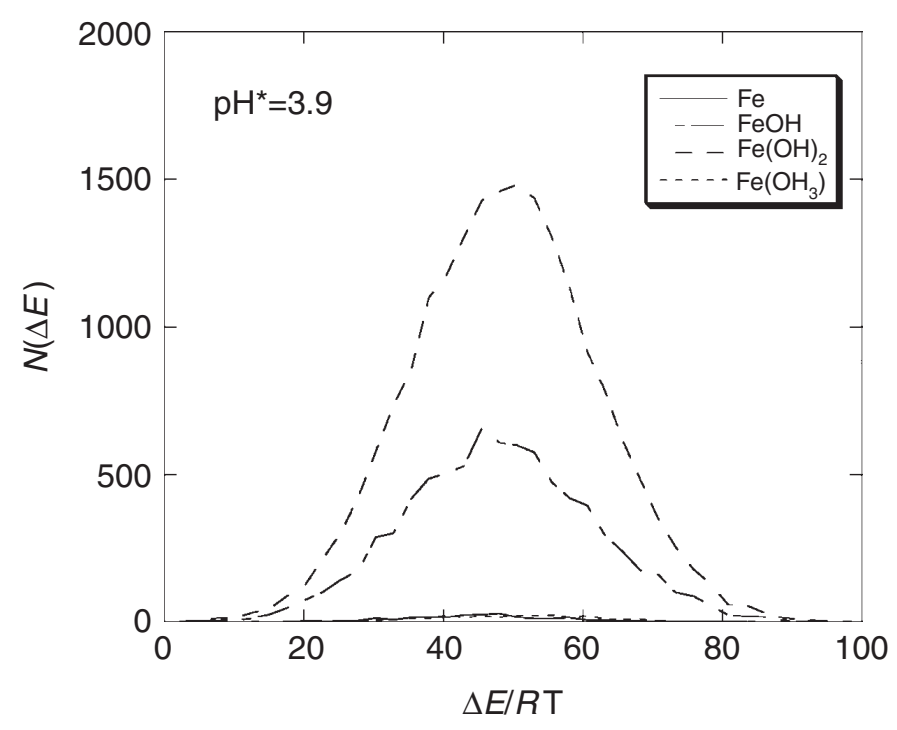

FIG. 6. Distribution of $\mathrm{Fe}^{2+} / \mathrm{Fe}^{3+}$ reorganization energies found in the MD simulation of electron transfer in a hydrolyzing solution of $\mathrm{Fe}^{3+}$ (the $\mathrm{Fe}^{2+}$ could hydrolyze, but never does) at an apparent $\mathrm{pH}$ near 3.9. The strongly overlapping distributions show almost no shift in reorganization energy as a function of hydrolysis, indicating that the hydrolysis fluctuations lie on a continuum with all other solvent fluctuations. 
electron transfer rate with increasing $\mathrm{pH}$ was the result of a particularly efficient hydrogen atom transfer pathway for exchange between $\mathrm{Fe}(\mathrm{OH})^{2+}$ and $\mathrm{Fe}^{2+}$.

\section{A.3. Titration of a polyoxocation in solution}

The extent of protonation of oxide surfaces has a fundamental influence on virtually every aspect of their chemical behavior in aqueous systems, governing dissolution/precipitation, sorption, and redox reactions, and controlling the mobility and aggregation state of colloidal-sized particles. The earliest approach to describing surface charging employed an effective "2-pK" model describing the $\mathrm{pH}$ of zero charge of the surface (26). In conjunction with assumptions about charge densities and surface capacitances, the $\mathrm{pH}$-surface charge relationship could be calculated from the two $\mathrm{p} K_{\mathrm{a}} \mathrm{s}$ of the model surface functional group (surface- $\mathrm{OH}_{2}^{+}$, surface$\mathrm{OH}$, and surface- $\mathrm{O}^{-}$). Many investigators have supposed that a better model of the surface could be obtained by explicitly taking into account the crystallographic heterogeneity of the surface sites, using the so-called "multisite" models (27). A molecular-level understanding of surface protonation reactions begins with some knowledge of which crystal facets define typical crystallite morphologies for a given mineral. The crystals are then cleaved parallel to these surfaces, several possible schemes for termination of the crystal structure are identified and guesses are made concerning the various types of oxide sites that will define the cleavage surface given a certain surface termination recipe. The $\mathrm{p} K_{\mathrm{a}}$ for each type of oxide site is estimated, and, given the relative surface areas of the facets defining the idealized crystal, the surface proton uptake and release can be estimated as a function of $\mathrm{pH}$.

Here again, quantum chemical calculations can be used to check the performance of the parameterized model on more complex molecules, used as surrogates for surface sites on oxides. Consider the $\mathrm{Fe}_{3}(\mathrm{OH})_{7}\left(\mathrm{H}_{2} \mathrm{O}\right)_{6}{ }^{2+}$ molecule in Fig. 7. The deprotonation energy for the $\mu_{3}-\mathrm{OH}$ site in this model molecule was calculated using the generalized gradient approximation in density function theory (DFT) and also with the conventional $\mathrm{Fe}^{3+}-\mathrm{O}-\mathrm{H}$ force field (28). Both calculations gave $179 \mathrm{kcal} / \mathrm{mol}$, showing that the model is capable of giving accurate results and is properly accounting for the influence of multiple $\mathrm{Fe}-\mathrm{O}$ bonds on the acidity of the $\mathrm{OH}$ functional group.

The multisite surface complexation model (MS-SCM) by Hiemstra, Van Riemsdijk, and Bolt (27) was the first effort directed at understanding the reactivity of an oxide surface in terms of heterogeneous array individual surface functional groups. These authors 


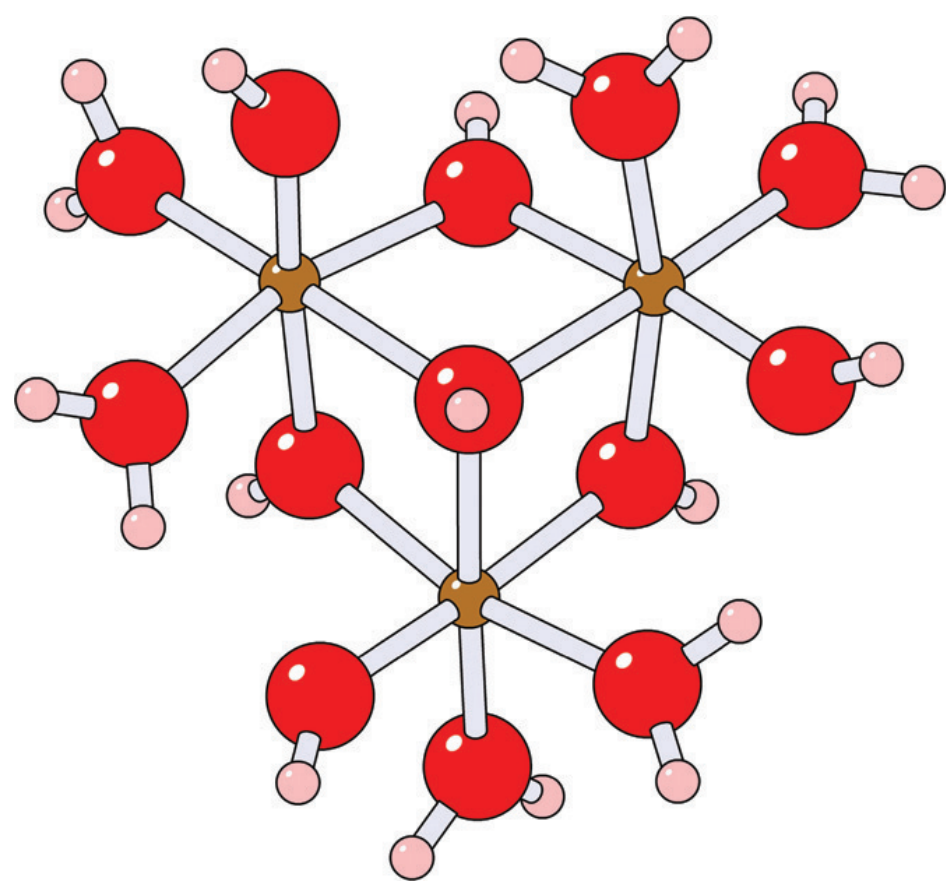

FIG. 7. $\mathrm{Fe}_{3}(\mathrm{OH})_{7}\left(\mathrm{H}_{2} \mathrm{O}\right)_{6}{ }^{2+}$ trimer used to compare gas-phase acidities of $\mathrm{m}_{3}-\mathrm{OH}$, groups between density functional theory and the MD model. The MD model and GGA DFT calculations both predict a gas-phase acidity of $179 \mathrm{kcal} / \mathrm{mol}$.

used the concept of total "bond valence" as governing the $\mathrm{p} K_{\mathrm{a}} \mathrm{s}$ of individual oxide sites on an oxide mineral surface. A simple definition of bond valence could be the sum of the formal charge divided by the coordination number (sometimes called the Pauling bond strength) over all cations attached to the oxide ion plus the -2 formal charge on the oxide ion. Roughly, the greater the Pauling bond strength contributed to the surface oxide ion, the more positive the bond valence at the oxide ion, and the greater the acidity. Parameterization of their MS-SCM model was based on an empirical relationship between the Pauling bond strength and $\mathrm{p} K_{\mathrm{a}}$ for oxo ions with known structure and $\mathrm{p} K_{\mathrm{a}}$. An early molecular modeling approach to this problem (29) used a parameterized molecular model constructed for the aqueous $\mathrm{Fe}^{3+}$ ion, showed that it gave reasonable predictions for the crystal structures of $\alpha-, \beta-$, and $\gamma-\mathrm{FeOOH}$, and used the model to calculate the gas-phase proton affinities of individual sites on several surfaces of goethite $(\alpha-\mathrm{FeOOH})$. Using an empirical relationship between the gasphase acidities of $\mathrm{Fe}\left(\mathrm{H}_{2} \mathrm{O}\right)_{6}{ }^{3+}$ and $\mathrm{Fe}(\mathrm{OH})_{3}$ and the solution $\mathrm{p} K_{\mathrm{a}}$. they were able to produce an MS-SCM by relating the calculated gas-phase proton affinities to solution $\mathrm{p} K_{\mathrm{a}}$. 
Although both of these approaches produced reasonable results, there was no real control on the types of functional groups present on the surface at the time, leading to difficulties in evaluating the sensitivity to different surface terminations that are to some extent chosen arbitrarily in the model. Early work attempting to search spectroscopically for the existence of $\eta-\mathrm{H}_{2} \mathrm{O}$, $\mu-\mathrm{OH}$, and $\mu_{3}-\mathrm{OH}$ groups on iron oxide and oxyhydroxide surfaces $(30,31)$ were difficult to interpret, because there was no convincing separation of the hydroxyl stretch frequencies that would allow identification of the different surface functional groups. Recent electronic structure calculations (32) show that the stretching frequencies of the $\eta-\mathrm{H}_{2} \mathrm{O}, \mu-\mathrm{OH}$, and $\mu_{3}-\mathrm{OH}$ groups are all within a few wave numbers of one another and would have been impossible to see with the resolution available using spectroscopic techniques in the 1970s.

The situation has improved with the advent of high-resolution $\mathrm{X}$-ray reflectivity studies (33) and high-resolution infrared spectroscopic methods (34) but most surface X-ray reflectivity studies are interpreted using fractional site occupancies, indicating a high density of defects on these surfaces giving rise to functional groups of unknown local structure and mutual arrangement. Knowledge of aqueous-mineral interfacial structures at the functional group level remains a difficult and elusive problem that may only be definable in a statistical sense. Even on simple oxides like $\mathrm{TiO}_{2}$, which has been extensively studied both theoretically and experimentally, the populations of functional groups on ultra-high vacuum systems with a single monolayer of water molecules have not been determined unequivocally (35).

These difficulties created an incentive to focus theoretical investigations on polynuclear ions, which were structurally well characterized, and, though innovative experimental studies using NMR to follow the dynamics of oxygen-isotope exchange processes were beginning to yield unprecedented details of elementary reactions in aqueous solutions (36).

One of the first computational tasks was to simulate the deprotonation of the surface of the $\mathrm{Al}_{30} \mathrm{O}_{8}(\mathrm{OH})_{56}\left(\mathrm{H}_{2} \mathrm{O}\right)_{26}{ }^{18+}\left(\mathrm{Al}_{30}\right)$ ion and the $\mathrm{Al}_{13} \mathrm{O}_{4}(\mathrm{OH})_{24}\left(\mathrm{H}_{2} \mathrm{O}\right)_{12}{ }^{7+}\left(\mathrm{Al}_{13}\right)$ ion using the techniques similar to those used on the $\mathrm{Fe}^{3+}$ ion described above. The structure of the $\mathrm{Al}_{30}$ ion, shown in Fig. 8, has been determined through X-ray diffraction studies on the sulfate hydrate salt $(37,38)$. A fully protonated $\mathrm{Al}_{30}$ ion was immersed in a solution of 18 perchlorate ions and brought to an equilibrium protonation state, where, in the neutral solution, it lost two protons, one from each of the S4 waters, illustrated in Fig. 8. Addition of hydroxide ions to the surrounding solution induced further deprotonation of the 

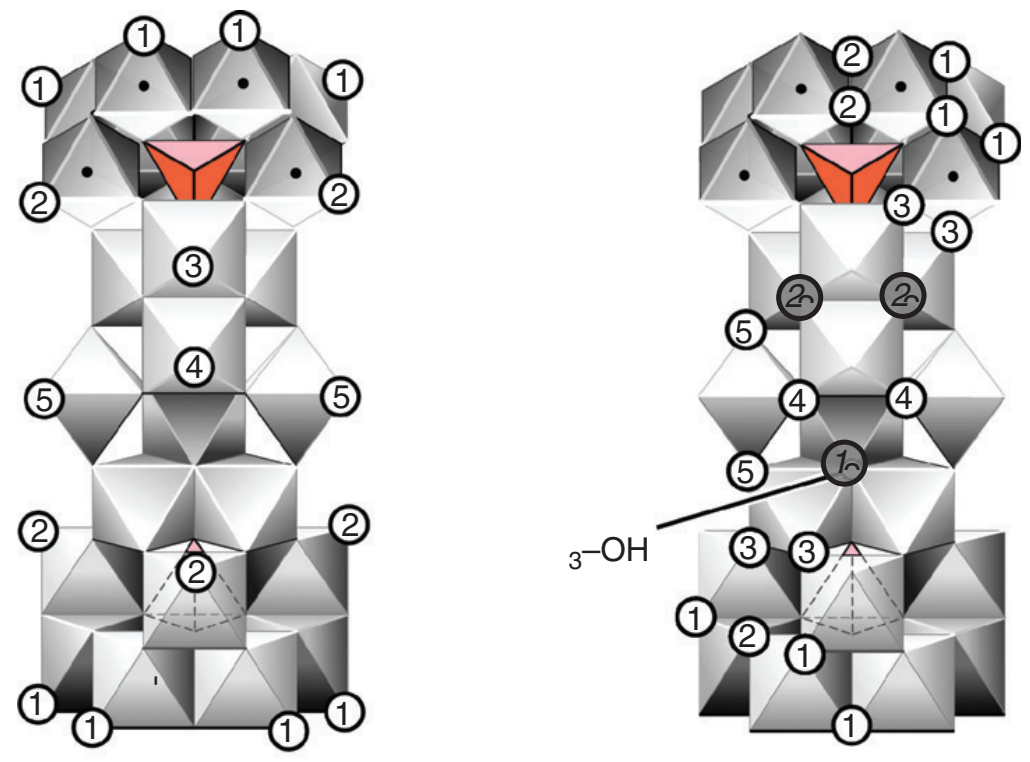

Sets of bound waters

Sets of $\mu-\mathrm{OH}$

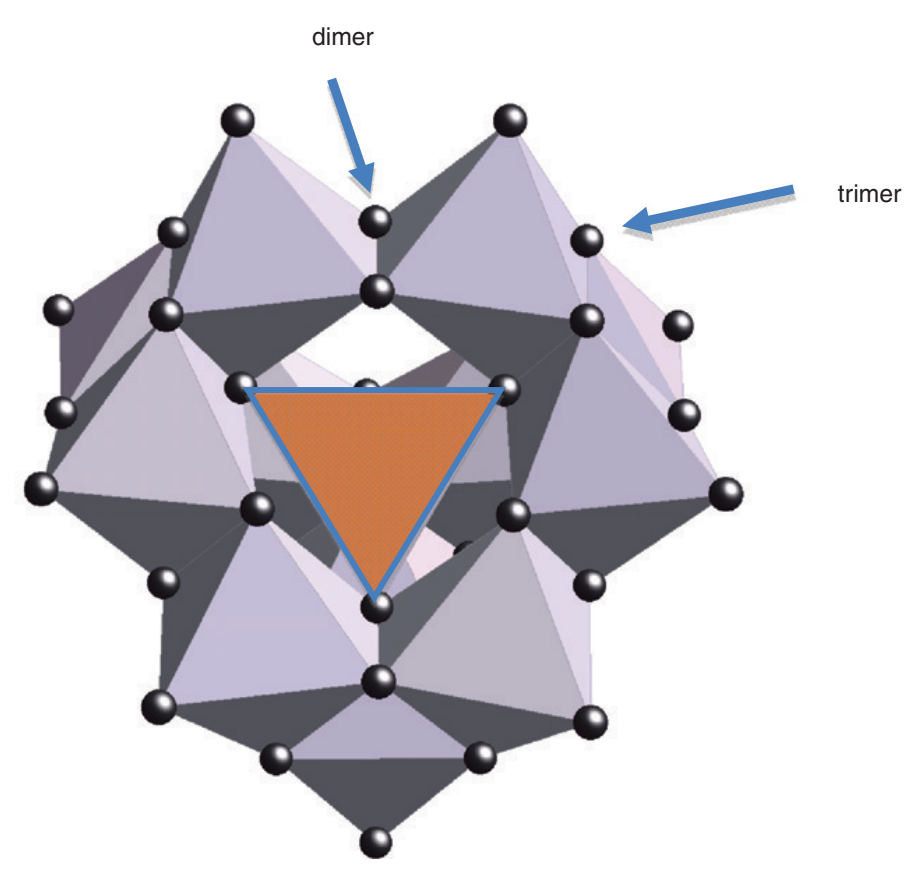

FIG. 8. $\mathrm{Al}_{30}{ }^{18+}$ (a) and $\mathrm{M}_{13}{ }^{7+}$ (b) polynuclear clusters. Sets of different oxygen sites (some are not shown) grouped together for identification. In the representation of the bridging hydroxide ions on the right, the doubly bridging sites $(\mu-\mathrm{OH})$ are shown with white circles and the triply bridging sites $\left(\mu_{3}-\mathrm{OH}\right)$ are shown in gray with identifying numbers in italics. The tetrahedral metal in the center of each $\delta$ - 13 unit is shown in orange. 


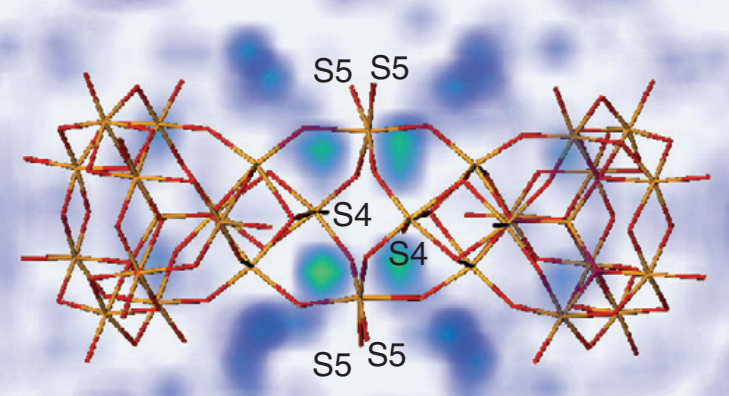

FIG. 9. Variation of water density around the $\mathrm{M}_{30}{ }^{18+}$ cation. Sites labeled S5 and S4 use the same numbers as used in Figure 8.

ion. The next sites to deprotonate were the four S5 waters, followed by the S1 and S2' sites. From an experimental point of view, the major problem is that these ions cannot deprotonate very much before they become unstable to flocculation, so the titrations can only take place over a limited range of $\mathrm{pH}$. Experimental measurement of the acidometric titration of the $\mathrm{Al}_{30}$ ion was reported in (39). Increasing $\mathrm{pH}$ above $\mathrm{pH}=4$ led to two protons being lost by $\mathrm{pH} 5$, with loss of an additional six protons by $\mathrm{pH}=5.5$, followed by a plateau with little proton loss until flocculation occurs near $\mathrm{pH}$ 6.5. Comparison of the simulation results with the measured titration curve indicated that the first plateau could be explained by relatively high acidities of the S4 and S5 sites. The major factor determining the relative acidities of the functional groups was the disposition of the hydrating waters in the central region of the molecule, as shown in Fig. 9. None of the $\mu$-hydroxo groups lost or gained a proton during the course of the simulation, despite the fact that these groups had relatively high gas-phase proton binding energies. The $\mu_{3}$-hydroxo functional groups did exchange protons with the solution on the timescale of the simulation, but because of their isolation from the solvent, and, hence, the difficulty of hydrating the deprotonated $\mu_{3}$-oxo site, were not a significant source of acidity for the $\mathrm{Al}_{30}$ ion. These calculations conclusively highlighted the importance of hydration forces and solvent accessibility in determining the relative acidities of the surface functional groups.

\section{A.4. Surface charge accumulation on $\alpha-\mathrm{FeOOH}$ nanoparticles}

Molecular dynamics simulations were used to compute proton distributions on faceted $\alpha-\mathrm{FeOOH}$ particles $3-8 \mathrm{~nm}$ in size (40). 
Model crystallites of $\alpha-\mathrm{FeOOH}$ were created with systematic variations in the ratio of the two commonly developed (021) and (110) facets. The model particles for the two extreme cases in large (long thin particle) and small (short fat particle) (110)/(021) surface area ratios are illustrated in Fig. 10. These particles were protonated to
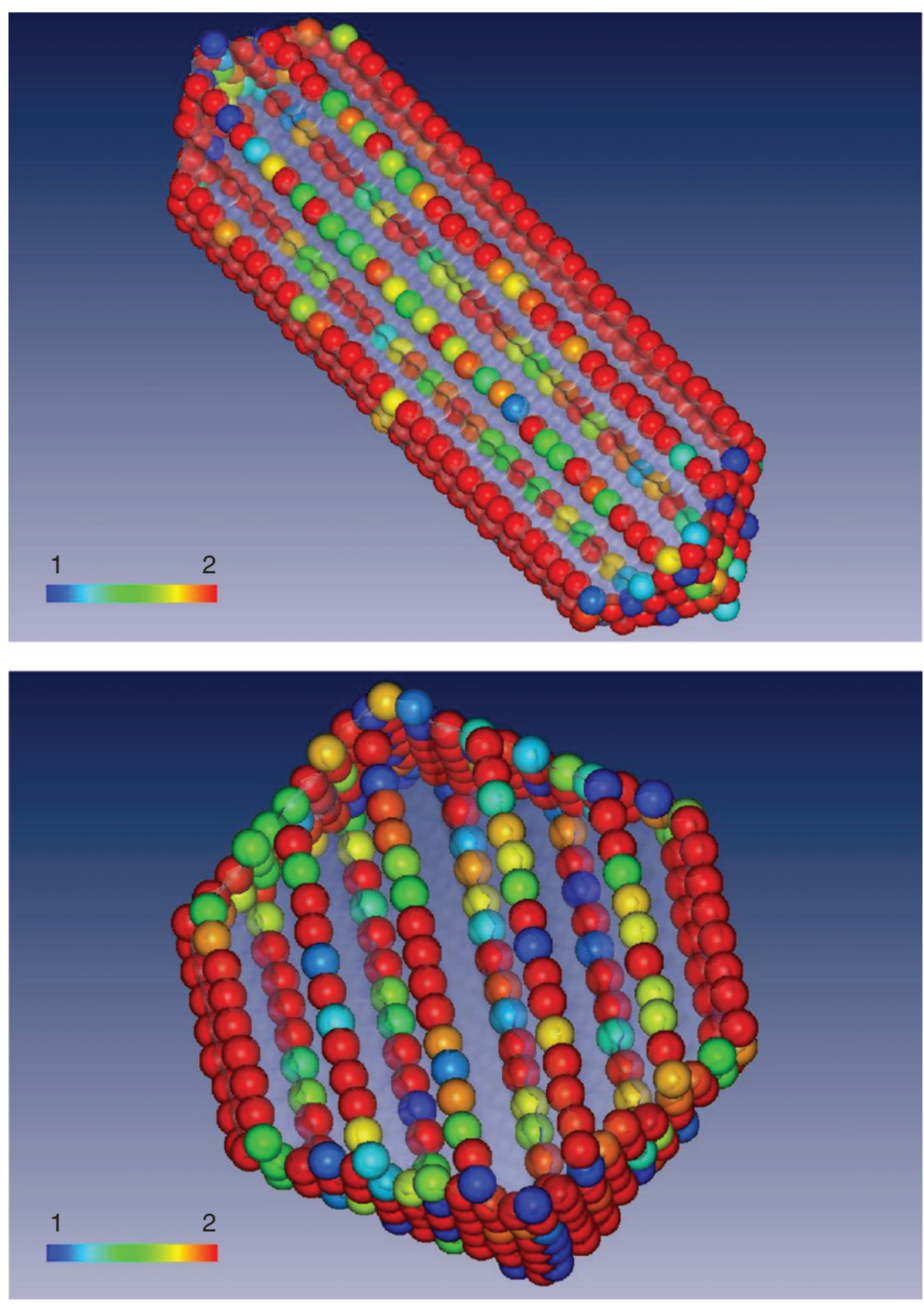

Fig. 10. Average protonation states of terminal $\eta-\mathrm{H}_{2} \mathrm{O}$ groups on model $\alpha-\mathrm{FeOOH}$ nanoparticles having high (a) and low (b) ratios of $(110) /(021)$ surfaces. Blue corresponds to an average protonation state of $1(\mathrm{FeOH})$ and red to an average protonation state of $2\left(\mathrm{FeOH}_{2}\right)$. 
neutrality and immersed in water (without counterions). The protonation states of the surface oxide ions was computed and indicated by the color coding in Fig. 10, with a protonation state of 2 corresponding to red and a protonation state of 1 corresponding to blue. Green would correspond to an average protonation state of 1.5. To provide a baseline for understanding the effect of crystal shape in governing the proton uptake, simulations were also carried out on idealized two-dimensional slabs representing the (021) and (110) crystal faces. The major finding is that, at these length scales, the simulated proton distributions do not at all reflect the sum of contributions from individual crystal faces. Instead protons accumulate preferentially at edge regions defined by the acute intersections of the (110)-( $\overline{10}$ ) surfaces. The effect was explained as resulting from the more effective solvation of excess charge at the acute edges of the particles and the tendency for surface charge to accumulate at sharp edges (41).

Studies of proton uptake on goethite have noted that surface roughness appears to have a noticeable effect on the total proton uptake, but little effect on the $\mathrm{pH}$ of zero charge (42). Variations in the amount of proton uptake on a suite of goethite particles were interpreted as being the result of variability in surface roughness $(42,43)$. The roughest surfaces were shown to have the largest proton uptake. The cause of this behavior was interpreted as a closer association of protons with the rough surfaces. The simulations on the model particles may indicate that the higher uptake of the rough surfaces is due to dielectric effects favoring proton accumulation in edge regions. In a system with background electrolyte, the electrolyte contribution to polarization around the surface charge would presumably also be enhanced in the edge region. Inhomogeneous proton accumulation on colloidal particles and rough surfaces would have broad implications for ligand exchange and electron transfer reactions. Because sites at acute edges are more accessible to protons, and have longer $\mathrm{Fe}-\mathrm{O}$ bonds to bound water sites, they should be preferentially reduced in oxidation-reduction reactions involving electron transfer from the solution phase to the solid phase. Similarly, electrons will be more mobile in edge regions for the same reason that decreasing $\mathrm{pH}$ increases ferrous-ferric exchange rates in homogeneous solution (23). Ligand exchange kinetics would be similarly enhanced due to the swelling effects and increased $\mathrm{M}-\mathrm{O}$ bond lengths at edge sites (44). The heterogeneity in the proton distributions will also influence the aggregation behavior of colloidal particles and provide a possible mechanism for electrostatic complementarity, allowing interparticle attachment pathways away from the point of zero charge. 
At some larger size, the behavior of the system overall must be predictable from the slabs; however, a detailed study of the mesoscale crystallography of goethite indicates the presence of pores on the (110) faces bounded by (021) surfaces (45). Any real system will likely have significant roughness on $10-\mathrm{nm}$ length scales, and hence, the edge effects highlighted in the simulations would still influence the charging behavior of the material. Thus, the calculations have some degree of generality and are not necessarily limited to the small length scales accessible through the simulations.

\section{B. Water, Hydroxide, and Oxide Exchange Kinetics}

\section{B.1. Polyoxocations}

The exchange of oxygen between water molecules in bulk solution and individual functional groups at a mineral surface is one of the most fundamental expressions of water-rock interaction. These reactions are central to a wide variety of geochemical processes, including dissolution, sorption, and colloid formation, yet little is known about the actual molecular pathways for exchange or even about the relative exchange rates at different coordination sites. Because there is so little information about mineral surface reactions at the molecular scale, the mechanisms have always been interpreted using ideas derived from studies of simple octahedral substitutions in monomeric aqueous complexes (46).

The coordination chemistry of oxygen atoms at a mineral surface would be expected to be much more complicated than that of a simple monomeric ion. Studies of oxygen isotope-exchange reactions in small aqueous clusters using nuclear magnetic resonance (NMR) spectroscopy provide a foundation for understanding ligand exchange kinetics in extended structures (36). Because the structures of the aqueous clusters are known, these studies allow reactions to be followed at individual sites. Rates of exchange of water molecules and hydroxyl bridges bound to metal ions with water molecules in the bulk solution were separately measured in these clusters. The clusters are 1-2 nm in size and were chosen because they have functional groups similar to those thought to be present at aluminum-hydroxide mineral surfaces.

B.1.a. Water exchange rates. Water-exchange rates are key guides of chemical reactivity in aqueous coordination compounds. Aqueous metal-ligand complexation reactions take place through the diffusion-limited formation of an electrostatic ion pair, 
followed by slow elimination of a water molecule bound to the metal center. This rate of the slow step is governed by the intrinsic water-exchange rate for the metal ion. Once the rate of water detachment is known, the rates of other ligand-exchange reactions usually can be estimated to within a factor of 10. Rates of surface complexation reactions at solid-water interfaces are intimately involved in diverse phenomena such as adsorption, electron transfer, and surface charging. There is no doubt that water-exchange rates are as fundamental to the reactivity of these systems as they are to coordination compounds, but, thus far, experimental determination of rates has been possible only for the simplest polynuclear systems.

Water-exchange rates for the $\mathrm{Al}^{3+}$ aquo ion, the $\mathrm{Al}_{13}$ and $\mathrm{Al}_{30}$ polynuclear ions discussed above, and models of clay mineral surfaces (gibbsite $\mathrm{Al}(\mathrm{OH})_{3}$, kaolinite $\mathrm{Al}_{2} \mathrm{Si}_{2} \mathrm{O}_{5}(\mathrm{OH})_{4}$, and boehmite $\mathrm{AlOOH})$ were determined computationally using molecular dynamics methods (44). Like the mineral surfaces, the polycations have water molecules bound at active sites that are separated by sets of relatively rigid hydroxyl bridges. Unlike the mineral surfaces, the polyoxocations have active sites whose arrangements are known from X-ray diffraction studies on hydrated salts of these ions. The molecular dynamics calculations were able to link these structurally diverse systems together into a simple structure-reactivity trend based on $\mathrm{Al}-\mathrm{OH}_{2}$ bond lengths and highlight the role of the $\mathrm{Al}_{13}$ and $\mathrm{Al}_{30}$ ions in systematically bridging the structural gap between the hexaaquo ion and the oxide surfaces.

As a general rule it should be expected that, in a series of polynuclear ions made from the same cation, the water molecules should exchange faster than they do for the monomeric aquo complex of the cation. The relevant experimental data for these clusters have been summarized in a recent review (36). Because the $\mathrm{Al}\left(\mathrm{H}_{2} \mathrm{O}\right)_{6}{ }^{3+}$ ion has the highest average charge per aluminum, the monomer should be the least reactive complex in the series. At $298 \mathrm{~K}$, the $\mathrm{Al}\left(\mathrm{H}_{2} \mathrm{O}\right)_{6}{ }^{3+}$ ion exchanges waters with a characteristic time of 1.2 seconds. The 12 bound waters on the $\mathrm{Al}_{13}$ class of complexes are all equivalent and, in keeping with this general rule, have characteristic exchange times between 0.0009 seconds and 0.005 seconds, depending on the identity of the central tetrahedral ion (aluminum, gallium, and germanium). For $\mathrm{Al}_{30}$, there are six distinct types of bound waters. Separate values cannot be assigned from the ${ }^{17} \mathrm{O}$ NMR experiments, although, overall, the timescales are consistent with a few milliseconds to tenths of milliseconds. Four of the bound waters, however, react so quickly that they 
could not be detected in ${ }^{17} \mathrm{O}$ NMR, which means that they exchange at least a factor of 10 more rapidly than the others.

Molecular dynamics calculations were carried out to estimate water exchange rates for surface sites on each of these species. The CLAYFF force field was used to do the calculations (47). This force field operates in conjunction with the SPC/E water model and was developed for simulating aluminum hydroxide minerals and clays. The authors used this force field because it was much less expensive than the Stillinger-David type force field described above, and, with long simulations, the temperature dependence of the rate could be obtained directly from rate calculations carried out at several temperatures, and, hence, the activation enthalpies and entropies, $\Delta \mathrm{H}^{*}$ and $\Delta \mathrm{S}^{*}$, could be determined. The measurements of water exchange rates take place in a $\mathrm{pH}$ region where acid-base reactions probably do not couple strongly with ligand exchange processes. For the $\mathrm{Al}_{13}{ }^{7+}$ and $\mathrm{Al}_{30}{ }^{18+}$ ions, charges on each of the aluminum ions were adjusted to reproduce the net charge on the complex. Water-exchange rates were calculated for each species using the reactive-flux method (48). In this method, an arbitrary reaction coordinate is expressed between the outgoing/incoming water molecule and the aluminum site to which it is attached. The potential of mean force along the reaction coordinate, W(r), was calculated using umbrella sampling, with 20-30 windows and a harmonic biasing potential. The rate constant is taken as $k_{\mathrm{RF}}=\kappa k_{\mathrm{TST}}$, where $k_{\mathrm{TST}}$ is the transition-state rate constant calculated from the potential of mean force and $\kappa$ is the transmission coefficient that accounts for barrier recrossing associated with the choice of reaction coordinate. The transmission coefficient is obtained by starting a series of simulations with the $\mathrm{Al}-\mathrm{H}_{2} \mathrm{O}$ distance balanced (and equilibrated) at the maximum in the potential of mean force, integrating forward and backward in time and counting the fraction of successful barrier crossings (49). The calculated rates are in reasonable agreement with the measured rates and, as shown in Fig. 11a, correlate well with calculated $\mathrm{Al}-\mathrm{OH}_{2}$ bond lengths on the exchanging sites. The slow rate of water exchange around the $\mathrm{Al}\left(\mathrm{H}_{2} \mathrm{O}\right)_{6}{ }^{3+}$ is consistent with the short $\mathrm{Al}-\mathrm{O}$ bond length calculated for the hexaaquo complex (1.83 calculated versus 1.88 measured). Calculations on the $\mathrm{Al}_{30}$ molecule reflect the site heterogeneity present in the $\mathrm{Al}_{30}$ ion. The slowest rates are for S3 and S4 (see Fig. 8), which have very short Al- $\mathrm{OH}_{2}$ bond lengths both in the simulation and in the X-ray structure. There is no experimental evidence for exchange rates as slow as those calculated; however, given the very short bond lengths observed for these sites, it is perhaps surprising that the NMR studies do 

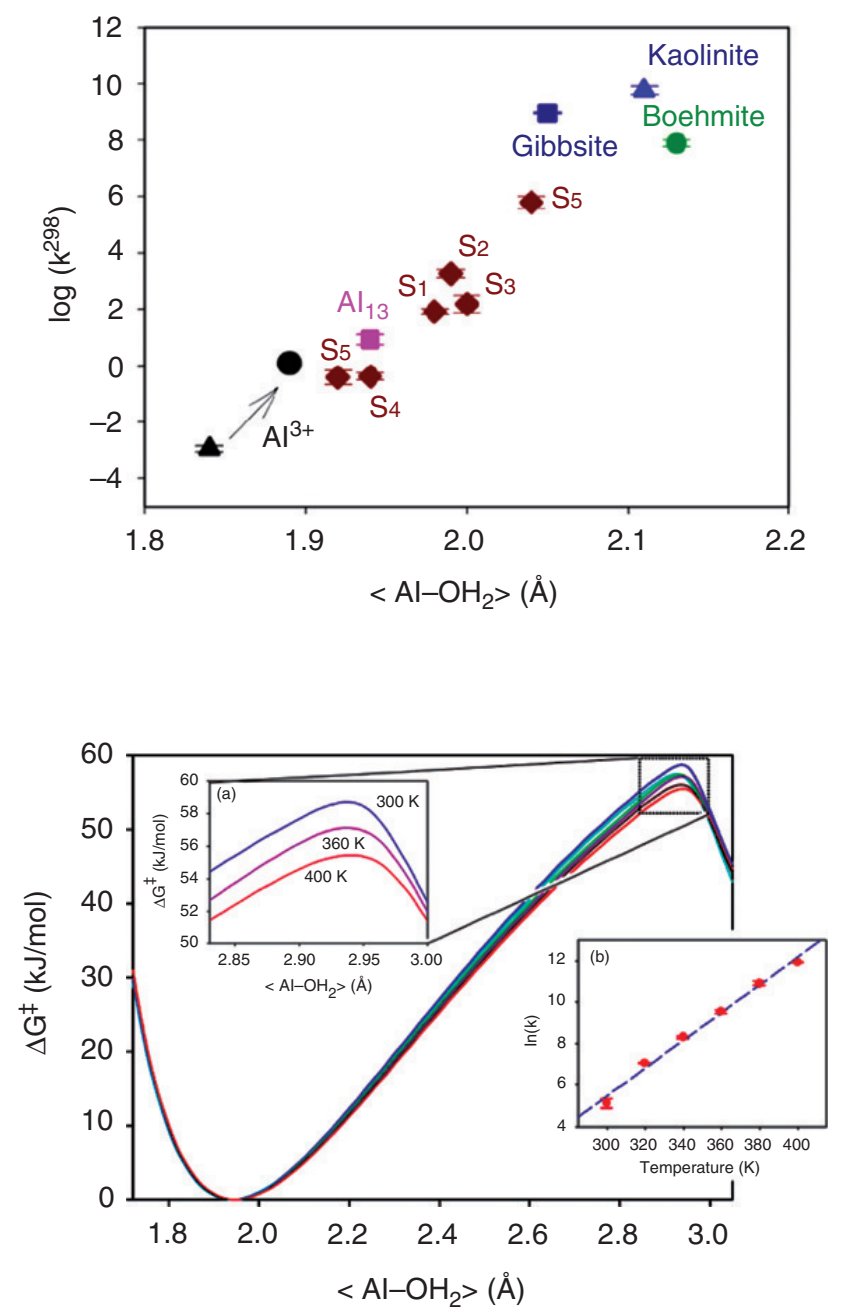

FIG. 11. (a) Correlation of calculated rate constant $\mathrm{k}$ at $298 \mathrm{~K}$ versus average $\mathrm{Al}-\mathrm{O}$ bond length on a series of polynuclear clusters and minerals. S1-S5 sites correspond with the notation given in Figure 8. (b) Temperature dependence in calculated potential of mean force and (inset) temperature dependence of the rate computed by integration of the potential of mean force.

not resolve two very slowly exchanging sites. The four symmetrically equivalent S5 sites exchange much faster than the other sites, consistent with the experimental observation that four waters are too reactive to measure with ${ }^{17} \mathrm{O}$ NMR.

The temperature dependence of the rate constants was used to determine the activation parameters (Figure 11b). Activation parameters have been measured for both $\mathrm{Al}\left(\mathrm{H}_{2} \mathrm{O}\right)_{6}{ }^{3+}$ and $\mathrm{Al}_{13}$. The calculated value of $\Delta \mathrm{H}^{*}$ for the $\mathrm{Al}\left(\mathrm{H}_{2} \mathrm{O}\right)_{6}{ }^{3+}$ ion $(101.5 \pm 2.6 \mathrm{~kJ}$ $\mathrm{mol}^{-1}$ ) is larger than the experimental value of $85 \pm 3 \mathrm{~kJ} \mathrm{~mol}^{-1}$, which again reflects the short $\mathrm{Al}-\mathrm{OH}_{2}$ bond length predicted by 
our modified CLAYFF force field for the $\mathrm{Al}^{3+}$ aquo ion. The ability of the umbrella-sampling approach to relate $\Delta \mathrm{H}^{*}$ to both the reaction coordinate and its associated transmission coefficient provides information complementary to the quantum mechanical studies, which neglect the transmission contribution. The relationship between $\Delta \mathrm{H}^{*}$ and the temperature dependence of the exchange rate is much clearer in the umbrella-sampling reactive-flux approach. The $\Delta \mathrm{H}^{*}$ of $64 \mathrm{~kJ} \mathrm{~mol}^{-1}$ calculated for the $\mathrm{Al}_{13}$ ion agrees well with the experimental values of $53 \pm 12$, $63 \pm 7$, and $56 \pm 8 \mathrm{~kJ} \mathrm{~mol}^{-1}$ for the $\mathrm{Al}_{13}, \mathrm{GaAl}_{12}$, and $\mathrm{GeAl}_{12}$ ions, respectively (36). Activation volumes for water exchange could be obtained through the pressure dependence of the calculated rate constant, analogous to Fig. 11. This has not been done for any of the polynuclear species discussed above, but the activation volume for water exchange around $\mathrm{Li}^{+}(\mathrm{aq})$ has been calculated in this way (50).

Overall, the estimates of the characteristic exchange times for the aluminous minerals are surprisingly short, falling within the range of $10^{-8}-10^{-10} \mathrm{~s}$, close to those for alkali and alkaline-earth metal ions. Waters bound at the edges of the minerals will exchange rapidly with bulk waters and with other ligands. The fast rates for these surface sites are consistent with the long $\mathrm{Al}-\mathrm{OH}_{2}$ bond lengths and also follow the general trend that rates increase, and $\Delta \mathrm{H}^{*}$ values decrease, with increasing size and decreasing charge per aluminum ion of the complex. This framework provides, for the first time, a means for estimating kinetic parameters for sites at aqueous polynuclear ions and oxyhydroxide surfaces. This result is an important step forward for environmental chemistry, where treatment of reaction kinetics at the aqueous-mineral interface is a long-standing problem.

B.1.b. Hydroxide bridge exchange on ( $\mathrm{Al}, \mathrm{Ga}, \mathrm{Ge}) \mathrm{Al}_{12} \mathrm{O}_{4}(\mathrm{OH})_{24}\left(\mathrm{H}_{2} \mathrm{O}\right)_{12}^{7+}$. In a series of groundbreaking experimental studies of single-site reactivity in polyoxocations, Casey and co-workers [see (36) for a review] determined the relative rates of hydroxide bridge exchange in a series of isostructural chemically substituted $\mathrm{MAl}_{12}{ }^{7+/ 8+}$ ions. These ions have the $\varepsilon$-Keggin structure shown in Fig. 8. There are two symmetrically unique hydroxide bridges, one connecting trimeric $\mathrm{Al}_{3}(\mathrm{OH})_{3}$ structures and another connecting the four trimers together with dimeric $\mathrm{Al}_{2}(\mathrm{OH})_{2}$ structures. The measurements showed that rates of exchange of the two hydroxide bridges in each Keggin ions were found to be independent of $\mathrm{pH}$ and to differ dramatically from one another by as much as a factor of 1000, with the dimeric bridges reacting faster. 
Moreover, the rates were extremely sensitive to a single metal substitution in the tetrahedral site at the center of the ion. These substitutions cause rates to differ by at least a factor of $10^{5}$ with bridge replacement rates increasing in the order $\mathrm{GaAl}_{12}<\mathrm{AlAl}_{12}$ $<\mathrm{GeAl}_{12}$. Because the central tetrahedral metal is three bonds away from the exchanging oxygen, it is surprising that the effect of substitution at the tetrahedral site is so strong.

Molecular dynamics simulations and electronic structure calculations showed that the observed reactivity trend arises because the central metal in the Keggin ion controls the formation of a hydrated metastable intermediate through polarization of the fourfold coordinated oxygen atoms $\left(\mu_{4}-\mathrm{O}\right)$ in each $\varepsilon$-Keggin structure (51). The mechanism involves bond rupture at two metal centers, partially releasing one of the "dimer" bridges, and allowing it to take on two waters of hydration to replace the broken $\mathrm{Al}-\mu_{4}-\mathrm{O}$ bonds and the resulting surface structure is stabilized by $\mathrm{H}_{3} \mathrm{O}_{2}$ bridges. This metastable intermediate then undergoes replacement of one of the $\mu-\mathrm{OH}$ functional groups with an $\mathrm{H}_{3} \mathrm{O}_{2}$ bridge. Exchange takes place as the metastable intermediate relaxes back to the $\varepsilon$-Keggin structure; each oxygen in the $\mathrm{H}_{3} \mathrm{O}_{2}$ structure has a $50 \%$ probability of being exchanged back out of the complex as it relaxes. The mechanism is illustrated in Fig. 12. The reason for the observed reactivity trend is simply that the stronger the tetrahedral $\mathrm{M}-\mu_{4} \mathrm{O}$ bond, the weaker the bond from the same $\mu_{4}-\mathrm{O}$ to the outer aluminum atoms, facilitating formation of the metastable intermediate. This idea is supported by the trends in $(\mathrm{Ga}, \mathrm{Al}, \mathrm{Ge})-\mu_{4} \mathrm{O}$ and $\mu_{4} \mathrm{O}-\mathrm{Al}$ bond lengths observed in X-ray diffraction studies on the $\varepsilon$-Keggin structures.

The reaction to form the hydrated intermediate has a high positive reaction volume $\left(\Delta V_{\text {rxn }}\right)$ relative to the stable $\varepsilon$-Keggin structure. This $\left(\Delta V_{\text {rxn }}\right)$ includes removal of two water molecules from the bulk solution that return the five-coordinated aluminums to their six-coordinated state. An additional water molecule is required to form the $\mathrm{H}_{3} \mathrm{O}_{2}$ bridge where the oxygen exchange takes place. The volume of the $\mathrm{Al}_{13}$ hydrated intermediate is $479 \mathrm{~cm}^{3} / \mathrm{mol}$ (using a probe radius of $1.4 \AA$ in the Connolly excluded volume calculation). This exceeds the volume of the stable $\mathrm{Al}_{13}$ ion by $78 \mathrm{~cm}^{3} / \mathrm{mol}$. Subtracting the volume of the three water molecules $\left(54 \mathrm{~cm}^{3} / \mathrm{mol}\right)$, a net $+24 \mathrm{~cm}^{3} / \mathrm{mol}$ is estimated for the activation volume of the reaction. The experimentally measured activation volume is $+7.1 \mathrm{~cm}^{3} / \mathrm{mol}$ (52). While an exact correspondence between the activation volume estimated from the pressure dependence of the rate constant and the approximate calculation based on Connolly 


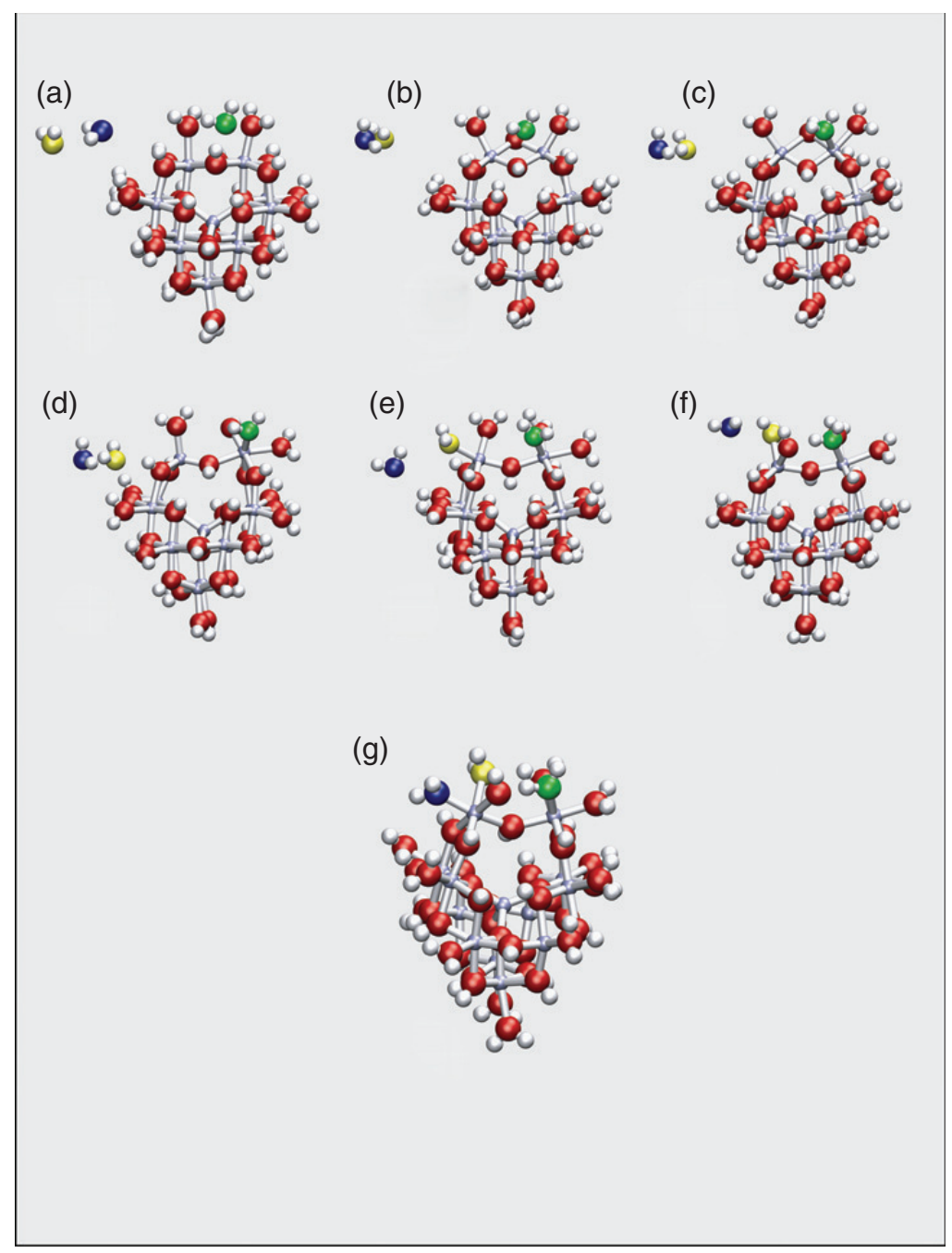

FIG. 12. Process of hydroxide exchange on dimer-bridging $\mathrm{OH}$ groups on the $\varepsilon$-Keggin ion through formation of a metastable intermediate. Oxygen atoms are red, protons are white, and trivalent metal atoms are gray. The green, blue, and yellow oxygen atoms progressively associate themselves in moving from $(\mathrm{a}-\mathrm{g})$ onto the metastable intermediate. Formation of the $\mathrm{H}_{3} \mathrm{O}_{2}$ bridge involving the green oxygen atom results in hydroxide exchange with $50 \%$ probability as the structure relaxes from (g) back to (a).

solvent-excluded volume would not be expected, the proposed mechanism predicts that rates of oxygen exchange at the $\mu$-O bridges in the $\mathrm{Al}_{13}$ will decrease with increased pressure and will be dominated by the large increase in volume to form the intermediate, consistent with the measured sign of the activation volume.

A corollary of the proposed mechanism is that solvation forces are important in stabilizing the hydrated intermediate. If the 
electrolyte distribution around the highly charged ion ties up water molecules needed for the stabilization of the intermediate, activation of the stable Keggin ion into the expanded intermediate will be inhibited. Therefore, a reduction in water activity should directly affect the formation of the intermediate complex facilitating the exchange. Any mechanism facilitated by the dissociative loss of a water molecule from the $\varepsilon$-Keggin structure would be consistent in sign with the measured activation volume, but should have an opposite response to an increase in ionic strength of the solution, as this effect should enhance the tendency for water loss from the complex. The concepts of dissociative and associative reactions, and the traditional interpretation of activation volumes in water exchange reactions, on simple aquo ions need to be revised when considering exchange in extended structures.

\section{Polyoxoanions}

Recent experimental studies on substituted decaniobate ions having the general formula $\mathrm{H}_{\mathrm{n}} \mathrm{Nb}_{10-\mathrm{m}} \mathrm{Ti}_{\mathrm{m}} \mathrm{O}_{28}^{-(6+m-n)}$ provide an opportunity to better understand the effect of protonation on oxygen exchange kinetics. While the solution stabilities of the polyoxocations discussed above decrease rapidly as they deprotonate, oxygen exchange reactions in the decaniobate and mono-titano and di-titano-substituted versions of the decaniobate ion can be followed over a range of $\mathrm{pH}$ conditions $(16,53)$. The experimental studies reveal substantial differences in the isotope exchange rates between the different oxygen atom types. The reactivity differences change with $\mathrm{pH}$. At $\mathrm{pH} 5.5$ where the molecule is $\sim 80 \%$ protonated, the rates are $\mu^{22}-\mathrm{O} \approx \eta^{2}-\mathrm{O} \approx \eta^{3}-\mathrm{O}>>\mu^{23}-\mathrm{O}>\mu^{12}-\mathrm{O}>\mu_{3}-\mathrm{O}>\mu_{6}-\mathrm{O}$ with the fastest reacting sites showing decreasing rates with increasing pH. From pH 7 to 9.5, the overall rates increase, and the relative values change somewhat becoming $\mu^{22}-\mathrm{O} \approx \eta^{3}-\mathrm{O}>\eta^{2}-\mathrm{O} \approx \mu^{23}-\mathrm{O}>\mu^{12}-\mathrm{O} \approx \mu_{3}-\mathrm{O} \approx \mu_{6}-\mathrm{O}$. This "amphoteric" behavior suggests the existence of both proton and hydroxide enhanced pathways in the exchange reactions.

The $\mathrm{Nb}^{+5}$ ion is unusual in that it appears to exhibit a degree of coordination frustration, in the sense of being too large for tetrahedral coordination, about also too small for optimal octahedral coordination, leading to structures, like those of $\mathrm{V}^{5+}$, where the "rattling" of the ion in an octahedral cage can have an important influence on bonding (54). These effects are evident in Fig. 4, showing the coordination structure of the decaniobate ion. 
It seems reasonable to suppose that the rattling of the small $\mathrm{Nb}^{5+}$ ion in its mismatched coordination sphere would figure prominently in governing the mechanism of oxygen isotope exchange. Fluctuations in the local coordination geometry of the $\mathrm{Nb}^{5+}$ would be expected to give rise to a marked time dependence of coordination number with instantaneous configurations closer to five-fold or four-fold coordination. During such fluctuations, the bond to the sixth oxygen atom would be stretched and vulnerable to attack. It is also during these excursions that the rattling $\mathrm{Nb}^{5+}$ might reopen its coordination sphere to an incoming nucleophile (hydroxide or water).

To better understand the possible weak links in the decaniobate ion that might give rise to oxygen exchange, a molecular dynamics calculation was carried out with the PQS quantum chemistry code (www.pqs-chem.com) of the decaniobate ion embedded in the COSMO continuum solvent model (55) (dielectric constant $=80$, probe radius $=1.4 \AA$ ). The time step was set at 0.001 picoseconds, and the simulation was run for 3000 time steps. The kinetic energy of the system was equivalent to $1000 \mathrm{~K}$ in temperature. During the dynamics, several excursions of the type shown in Fig. 13 were observed, where the $\mathrm{Nb}_{3}-\mu_{3} \mathrm{O}$ bond would break, the $\mathrm{Nb}_{3}$ niobium would pass through a five-fold coordinate intermediate in Fig. 13(b), and become tetrahedrally coordinated as illustrated in Fig. 13(c). The average bond lengths and the fractional average fluctuations are given in Table IV. The calculation confirms that the bonds most susceptible to breaking are the $\mathrm{Nb}_{3}-\mu_{3}-\mathrm{O}$ bonds on the top of the molecule. That the $\eta_{3}-\mathrm{O}$ exchanges should be relatively fast fits in well with this finding. However, the fastest oxygen atoms to exchange over most of the $\mathrm{pH}$ range are the $\eta_{2}-$ $\mathrm{O}$ and $\mu^{22}-\mathrm{O}$ oxygen atoms and these have the smallest RMS bond fluctuations during the simulation. Based on Table IV, it might be guessed that the $\mu^{12}-\mathrm{O}$ and $\mu_{3}-\mathrm{O}$ would exchange more quickly than the $\mu^{22}-\mathrm{O}$.

Molecular dynamics simulations of the decaniobate ion were carried out using the conventional MD model described above with 250 solvating waters (16). With no added hydroxide or protons, the molecule was stable over $10 \mathrm{~ns}$ simulation times. Average bond lengths and fluctuations are given in Table IV, and, in a relative sense, compare well with the DFT direct dynamics, given that the RMS fluctuations in bond length are smaller because of the much lower temperature. Thus the same general conclusions/expectations discussed for the direct dynamics calculation would hold for the conventional MD calculation. 

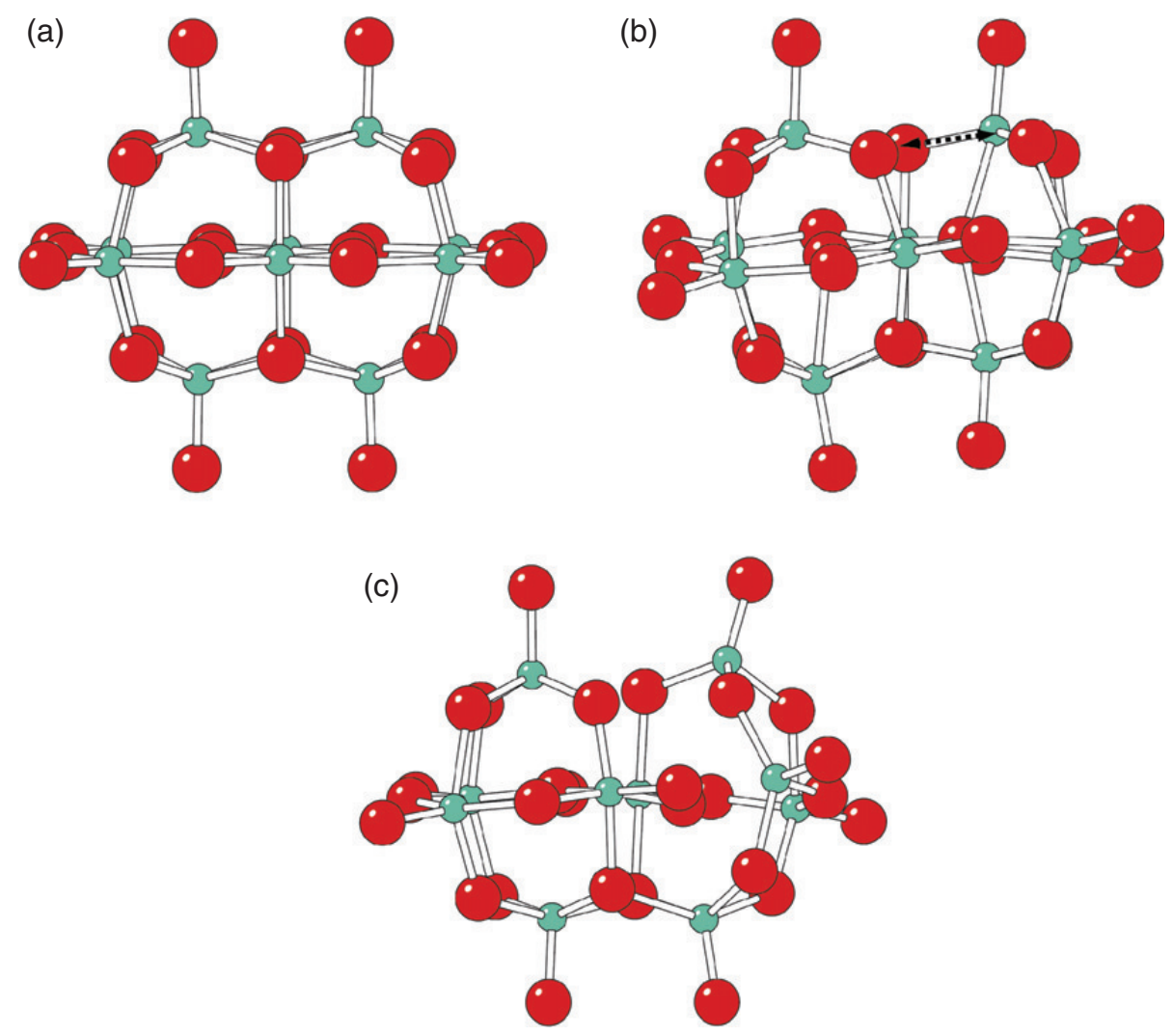

Fig. 13. Coordination fluctuations of $\mathrm{Nb}^{5+}$ in the decaniobate ion during a molecular dynamics calculation of the decaniobate ion in continuum solvent. Oxygen atoms are red, and niobium atoms are green. The dynamics are characterized by frequent $\mathrm{Nb}-\mu_{3}-\mathrm{O}$ bond ruptures, as shown in (b), followed by instantaneous tetrahedral coordination for the $\mathrm{Nb}_{3}$, shown in (c). See Figure 4 for description of notation.

To obtain more information on the hydroxide-enhanced pathway at high $\mathrm{pH}$, a single hydroxide ion was added to the solution. After several nanoseconds of simulation time, the ion began to break down by the process illustrated in Fig. 14. This is initiated by hydroxide attack on $\mathrm{Nb}_{1}$ in the region where the two $\mu^{12}-\mathrm{O}$ and $\mu_{3}-\mathrm{O}$ atoms come together on one of the outer octahedral faces of $\mathrm{Nb}_{1}$. At this point, $\mathrm{Nb}_{1}$ becomes disconnected from the $\mu_{3}-\mathrm{O}$ atom at the top of the decaniobate ion as well as the two $\mu_{6}-\mathrm{O}$ atoms at the center of the ion as shown in Fig. $14 \mathrm{~b}$. The $\mathrm{Nb}_{1}$ ion is tetrahedrally coordinated at this point and begins to hydrate with water molecules shown in blue, increasing its coordination number. $\mathrm{Nb}-\mathrm{OH}_{2}$ functional groups are highly acidic, and as the hydration waters are progressively attached to the "pulled out" $\mathrm{Nb}_{1}$ they lose protons. These protons then become available to protonate other oxygen sites on the 
TABLE IV

Bond Lengths and Their Root Mean Square Fluctuations for the Decaniobate Ion in Figure 4 as Predicted From Molecular Dynamics Calculations

\begin{tabular}{|c|c|c|c|c|c|c|}
\hline & \multicolumn{3}{|c|}{$\begin{array}{l}\text { DFT } \\
\text { COSMO (1000 K) }\end{array}$} & \multicolumn{3}{|c|}{$\begin{array}{l}\text { Parameterized MD model } \\
\text { Explicit Water }(300 \mathrm{~K})\end{array}$} \\
\hline & $<\mathrm{r}>$ & RMS & $\mathrm{RMS} /<\mathrm{r}>$ & $\langle\mathrm{r}\rangle$ & RMS & $\mathrm{RMS} /<\mathrm{r}>$ \\
\hline $\mathrm{Nb}_{3}-\mu_{3}$ & 2.28 & 0.347 & 0.152 & 2.19 & 0.071 & 0.033 \\
\hline $\mathrm{Nb}_{3}-\mu^{23}$ & 1.96 & 0.087 & 0.045 & 1.96 & 0.030 & 0.015 \\
\hline $\mathrm{Nb}_{2}-\mu^{23}$ & 2.05 & 0.115 & 0.056 & 2.02 & 0.036 & 0.018 \\
\hline $\mathrm{Nb}_{2}-\mu^{22}$ & 2.01 & 0.114 & 0.056 & 2.00 & 0.036 & 0.018 \\
\hline $\mathrm{Nb}_{3}-\eta^{3}$ & 1.78 & 0.042 & 0.024 & 1.87 & 0.021 & 0.011 \\
\hline $\mathrm{Nb}_{2}-\eta^{2}$ & 1.79 & 0.063 & 0.035 & 1.88 & 0.021 & 0.011 \\
\hline $\mathrm{Nb}_{1}-\mu^{12}$ & 1.89 & 0.067 & 0.036 & 1.93 & 0.025 & 0.013 \\
\hline $\mathrm{Nb}_{2^{-}} \mu^{12}$ & 2.18 & 0.177 & 0.082 & 2.10 & 0.048 & 0.023 \\
\hline $\mathrm{Nb}_{1}-\mu_{6}$ & 2.25 & 0.171 & 0.076 & 2.21 & 0.071 & 0.032 \\
\hline $\mathrm{Nb}_{1}-\mu_{3}$ & 2.07 & 0.131 & 0.063 & 2.11 & 0.050 & 0.024 \\
\hline
\end{tabular}

decaniobate ion and can be quickly transferred to other surface sites through the Grothuss mechanism. As shown in Fig. 14d, the $\eta^{2}-\mathrm{O}$ groups become protonated in the conventional MD model. The parameterized model does not do very well on the terminal oxygen atoms, giving $\mathrm{Nb}_{2}-\eta^{2}-\mathrm{O}$ and $\mathrm{Nb}_{3}-\eta^{3}-\mathrm{O}$ bonds that are too long, and probably have too high of a proton affinity. It is difficult to even check how inaccurate the proton affinities might be for the model decaniobate ion because the COSMO continuum solvation model has not been implemented in the MD force field. Therefore, unlike the hexaaquo cation and oxyanion systems described above, there is no possibility of a direct comparison between the gas-phase proton affinities of the decaniobate ion; the anions are not even stable in the absence of solvation, which must be taken into account by a continuum solvent model in the DFT studies and by using real water molecules in the conventional molecular dynamics. This is where the theoretical disadvantages of working on large anions become particularly inconvenient, as it is hard to compare these methods quantitatively.

It remains difficult to understand how this sequence of events would lead to a particularly fast exchange rate of the $\mu^{22}-\mathrm{O}$ and $\eta^{2}$-O sites. If anything, the pathway indentified by the MD simulations would suggest that the $\eta^{3}-\mathrm{O}$ and $\mu_{3}-\mathrm{O}$ exchange the most rapidly. A working hypothesis is that perhaps the proton affinity of the $\mu^{22}-\mathrm{O}$ site is large relative to the other sites, and if this site 


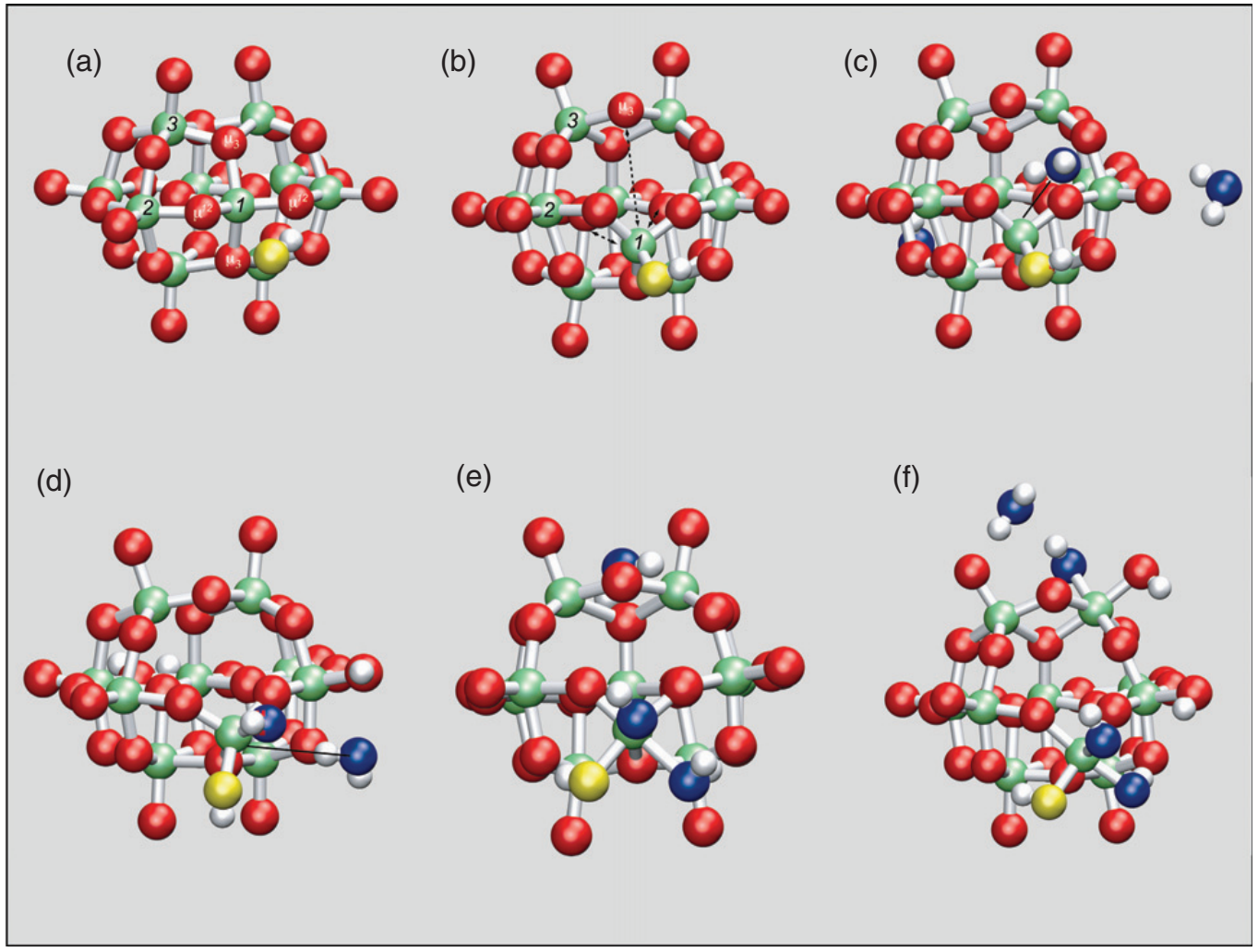

FIG. 14. Formation of metastable intermediate revealed in a classical molecular dynamics simulation of the decaniobate ion under basic conditions. Oxygen atoms are red, niobium atoms are green, and protons are white. The added hydroxide ion is represented by the yellow oxygen. $\mathrm{Nb}_{1}$ is nucleophilically attacked by the hydroxide ion in (b), and the upper bond to the $\mathrm{m}_{3}$ and the bonds to the $\mathrm{m}_{6}$ oxygen atoms in the center of the ion are broken. The displaced niobium atom then proceeds to hydrate, with the waters represented by the blue oxygen atoms becoming progressively attached, and then hydrolyzing to release protons that can bind to other oxygen atoms on the decaniobate. Water molecules also hydrate the top $\mathrm{Nb}_{3}$ atoms as they become detached from the central $\mathrm{m}_{6}$ oxygen atoms after the $\mathrm{Nb}_{1}-\mathrm{m}_{3} \mathrm{O}$ bond is ruptured.

receives protons emitted by the water molecules hydrating the intermediate state in Fig. 14, or some other analogous intermediate state, the exchange rate of these bridges would be accelerated. But there is no direct evidence of this in the calculations, and it is also possible that there exists a completely unrelated pathway that has not been identified in the MD simulations. At this point, the parameterized model has taken the theoretical work as far as it can, and the problem becomes a good task for AIMD. 
The system is a large one for AIMD and using AIMD to search for reaction paths in such systems is a very computationally intensive process. It is possible that the structures located with the parameterized model might prove to be good starting points for finding reaction pathways in the AIMD studies.

However, the fact that the weak bonds in the decaniobate ion are distant from the most rapidly exchanging ions echoes the mechanism of hydroxide exchange identified for the $\varepsilon$-Keggin ion strongly suggests that, again, a metastable intermediate plays a governing role in the pathways of oxygen exchange. If the mechanism were purely a local one, it seems almost certain that the $\eta_{3}-\mathrm{O}$ and $\mu_{3}-\mathrm{O}$ sites would exchange faster than the others, since, as indicated in both the DFT studies and the conventional MD model, this is where the direct action seems to take place in the decaniobate ion in its unperturbed state.

\section{Geological Problems with Molecular Level Solutions}

The term "molecular geochemistry" is easier on the ear than "molecular geology". The reason for this is probably that applications of the physical chemistry of interfaces to real geological problems are few. Most of the justification for building a better understanding of mineral-water interfacial processes has come from the standpoint of contaminant fate and transport in the Earth's subsurface. Such applications are societally important but will never have a transformative influence on our understanding of the history and behavior of the earth. Is there any indication that molecular-level knowledge of mineral-water interface geochemistry will have an influence on our ability to read the rock record more accurately and with greater precision?

\section{A. Boron Isotopes in Marine Minerals}

One example where computational chemistry has made a remarkable contribution to understanding the history of the earth is in the field of boron isotope geochemistry. Boron exists in the oceans as both $\mathrm{B}(\mathrm{OH})_{3}$ and $\mathrm{B}(\mathrm{OH})_{4}{ }^{-}$. The $\mathrm{p} K_{\mathrm{a}}$ of boric acid $(\sim 8.8)$ is such that both boric acid and borate are present in the $\mathrm{pH}$ ranges near that of seawater (7.5-8.5). Carbonate minerals forming in marine environments incorporate trace amounts of boron into their structures during growth, presumably through incorporation of the charged $\mathrm{B}(\mathrm{OH})_{4}{ }^{-}$species. Because boric acid 
and borate should have different affinities for ${ }^{11} \mathrm{~B}$ and ${ }^{10} \mathrm{~B}$, it has been proposed that measurement of the isotopic composition of boron trapped in ancient carbonate minerals, which is assumed to give the boron isotopic composition of only borate, could conceivably be used to estimate the $\mathrm{pH}$ of ancient seawater (56). Since the $\mathrm{pH}$ of seawater is directly related to atmospheric $\mathrm{PCO}_{2}$, the technique can be used to estimate the $\mathrm{PCO}_{2}$ of the atmosphere over time scales corresponding to the residence time of boron in the oceans, roughly 15 million years (we need to know the overall boron isotopic composition of the entire ocean to apply the method). Given concerns over rising levels of atmospheric $\mathrm{CO}_{2}$ concentrations, the history of $\mathrm{PCO}_{2}$ of the atmosphere on geological timescales is an important geological problem.

To carry out such an estimate, the equilibrium constant $\mathrm{K}_{34}$ for the reaction given in Equation (11) must be known:

$$
{ }^{10} \mathrm{~B}(\mathrm{OH})_{3}+{ }^{11} \mathrm{~B}(\mathrm{OH})_{4}^{-}={ }^{11} \mathrm{~B}(\mathrm{OH})_{3}+{ }^{10} \mathrm{~B}(\mathrm{OH})_{4}{ }^{-}
$$

Until recently, the only value available for $\mathrm{K}_{34}$ was estimated from the measured vibrational frequencies of the boric acid and borate ions (57). These frequencies were used to build a valence force field for borate and boric acid, which was then used to calculate the vibrational partition functions for both ions, and, hence, $\mathrm{K}_{34}$, yielding a value of 1.019 (in other words, boric acid is enriched in ${ }^{11} \mathrm{~B}$ relative to borate under equilibrium conditions). This approach was used to infer more acidic ocean $\mathrm{pH}$ values $(\mathrm{pH}<7.5) 20$ million years in the geologic past. More recent quantum-mechanical calculation of the vibrational partition functions $(58,59,60,61)$ indicated that the equilbrium constant is near 1.025-1.030, much higher than previously thought. The quantum chemical calculations motivated, and were corroborated by careful experiments in which the small shift in $\mathrm{p} K_{\mathrm{a}}$ of $\mathrm{B}(\mathrm{OH})_{3}$ with boron-isotope substitution was used to determine $\mathrm{K}_{34}(62)$. More recently, ab initio molecular-dynamics calculations (63) showed that the reason for the discrepancy with the small $\mathrm{K}_{34}$ value was because the strongly fractionating asymmetric stretching vibration had been incorrectly assigned and, thus, completely missed. The new value for $\mathrm{K}_{34}$ (1.028) implied that the $\mathrm{pH}$ of the Miocene oceans was not 7.5, but closer to 8.5. In an ironic illustration of an interdisciplinary "house of cards", interpretation of 20 million years of the earth history was called into question because of the misassignment of a single vibrational frequency for $\mathrm{B}(\mathrm{OH})_{4}^{-}$. It is even more remarkable that the discrepancy was initially discovered through computational chemistry. Interestingly, the geological community had managed to mold their interpretations 
around a completely erroneous estimate of the equilibrium constant, causing some vigorous discussion in the geochemical literature as the basis for the boron-isotope $\mathrm{pH}$ proxy began to unravel $(64,65,66)$.

Building a more accurate boron-based paleo $\mathrm{pH}$ meter requires a much more detailed knowledge of the crystallographic structure of boron incorporated into calcite (67) and a more complete knowledge of how the boron actually passes from aqueous solution into the mineral. For example, it might not be true that all the boron incorporated into the structure comes from $\mathrm{B}(\mathrm{OH})_{4}{ }^{-}$. or, it may be that the isotopic composition of $\mathrm{B}(\mathrm{OH})_{4}^{-}$in calcite differs systematically from that of $\mathrm{B}(\mathrm{OH})_{4}{ }^{-}(\mathrm{aq})$. In other words, successful application of such "geoforensics" involves molecular-level tools that have to be well understood from a physicochemical point of view. Conversely, the vastness of geologic time has a way of making inadequacies in our understanding of physicochemical laws evident, sometimes at a very fundamental level (Kelvin's estimate of the age of the earth in the absence of radioactive heating being the classic example). The earth can be regarded as a vehicle for exploring reaction dynamics on immense timescales unavailable to direct experiment $(68,69)$. Thus the interdisciplinary conversation between physical chemistry and geology may be more of an exchange than a lecture.

\section{B. Carbon Isotopes In Soil Minerals}

Another geochemically based technique for reconstructing the $\mathrm{PCO}_{2}$ of the earth's atmosphere involves the determination of the mixing profile of atmospheric and microbial $\mathrm{CO}_{2}$ sources in soils $(70,71)$. It has been known for a long time that $\mathrm{CO}_{2}(\mathrm{~g})$ is enriched in ${ }^{13} \mathrm{C}$ relative to organic matter $(72)$. This can be understood in terms of the weaker bonding environment present in, for example, proteins, relative to inorganic forms of carbon $(73,74)$. However, atmospheric $\mathrm{CO}_{2}(\mathrm{~g})$ is heavier than microbial $\mathrm{CO}_{2}(\mathrm{~g})$ because the microbial $\mathrm{CO}_{2}$ can be thought of as fresh from the reservoir of isotopically light organic reservoir. During periods of high $\mathrm{PCO}_{2}$ in the atmosphere, the soil is more strongly dominated by the isotopically heavy atmospheric signature. If atmospheric $\mathrm{PCO}_{2}$ is small, the soil is more strongly dominated by the isotopically light microbial signature. Some of the $\mathrm{CO}_{2}(\mathrm{~g})$ is taken up by carbonate and oxide/oxyhydroxide minerals forming in soils. The carbon isotope profile imprinted in the minerals forming in the soil, and the shape of the isotopic profile have been used to estimate atmospheric $\mathrm{PCO}_{2}(70,71)$. 
A key question is then the relationship between the isotopic composition of the $\mathrm{CO}_{2}(\mathrm{~g})$ in the soil and the $\mathrm{CO}_{2}$ "dissolved" in the mineral species growing in the soils. The equilibrium carbon isotope fractionations between $\mathrm{CO}_{2}(\mathrm{~g})$ and carbonate minerals $\left(\mathrm{CaCO}_{3}\right.$ (both calcite and aragonite polymorphs), $\mathrm{MgCO}_{3}$ (magnesite)) are known experimentally and can be accurately calculated from quantum chemistry (75). Overall, carbon in carbonate minerals is isotopically heavier than carbon in $\mathrm{CO}_{2}(\mathrm{~g})$ by about $0.1 \%$ (10 per mil, in the usual units used by isotope geochemists) with smaller variations among the individual carbonate minerals. For oxide/oxyhydroxide mineral species, such as goethite $(\alpha-\mathrm{FeOOH})$, the fractionations were not known and initially assumed to be close to zero (i.e., the equilibrium constant for isotope exchange was assumed to be close to 1.000) (71). Later, it was found that a positive fractionation of $0.25 \%$ (with the goethite heavier in ${ }^{13} \mathrm{C}$ than the $\mathrm{CO}_{2}$ ) appeared to fit best within geologic constraints (76). There has to be some degree of circularity in using geological evidence to infer both the extent of the isotope fractionation and the $\mathrm{PCO}_{2}$ level. Quantum mechanical calculations of the equilibrium constant were carried out to gain additional insight into the issue (77).

In contrast to the carbonate minerals, where all the carbon is in the form of carbonate ions in a known arrangement, the structure of the dissolved $\mathrm{CO}_{2}$ component of goethite is not known. Knowledge of the structure is needed to carry out vibrational calculations to estimate the isotopic fractionations. Early studies, based on infrared vibrational spectroscopy, suggested that the carbonate was located in the open channels that are a prominent feature of the goethite structure (78). Later studies, using higher-resolution 2-D correlation methods, indicated a more complex speciation (79). To locate potential structures for $\mathrm{CO}_{2}$ dissolved in carbonate $\left(\mathrm{CO}_{2}(\mathrm{~m}) ; \mathrm{m}\right.$ for mineral), ab initio molecular dynamics simulations were carried out for a variety of possible initial configurations representing substitutions (a) $\mathrm{C}^{4+}=4 \mathrm{H}^{+}$ and (b) $\mathrm{C}^{4+}=\mathrm{M}^{3+}+\mathrm{H}^{+}$, as a sort of "conformer searching" procedure. These calculations were carried out in $\alpha-\mathrm{AlOOH}$, because treating $\mathrm{FeOOH}$ with the plane-wave density functional theory is very expensive, especially when including exact exchange in the functionals (which is required if it is desired that $\mathrm{FeOOH}$ be nonmetallic). As shown in Fig. 15, two basic structures were identified: one for starting configuration (a), in which the carbon occupied the open channel site, as envisioned in the early spectroscopy work, and another for starting configuration (b), in which the carbon was embedded in one of the faces of the vacant octahedron created by removing the $\mathrm{Al}^{3+}$. 
(a)

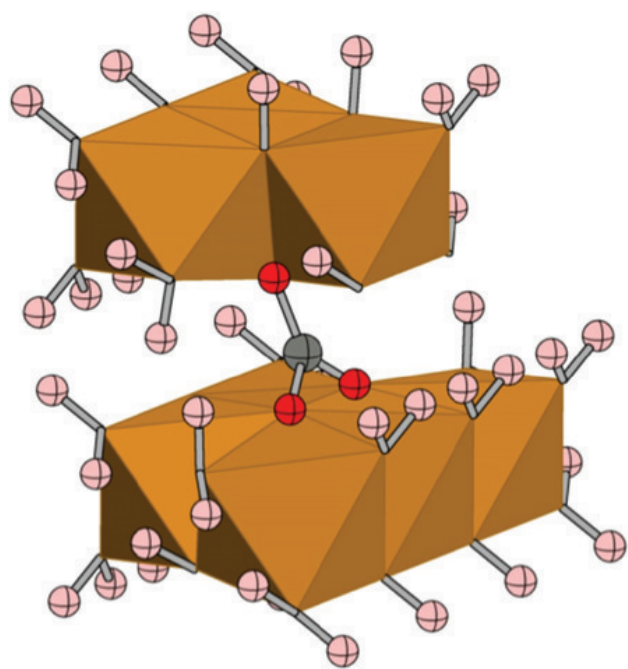

(b)

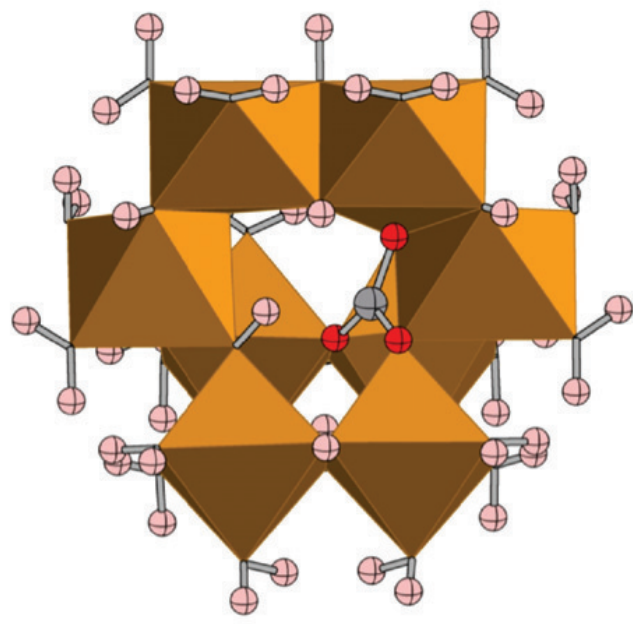

FIG. 15. Two possible configurations of carbon dioxide dissolved in goethite. Brown octahedra are $\mathrm{Fe}^{3+}$ centered octahedra making up the goethite structure, $\mathrm{C}^{4+}$ is shown in gray, oxygen atoms attached to $\mathrm{C}^{4+}$ are shown in red. Configurations are shown as (a) as a carbonate-like ion straddling the open channels, replacing three protons parallel to the b crystallographic axis in the goethite structure (b) embedded in the face of a vacant octahedron resulting from a $\mathrm{Fes}^{3+}$ vacancy. Each of the structures requires the removal of an additional proton.

Using the defect structures observed for $\mathrm{CO}_{2}(\mathrm{a})$ and $\mathrm{CO}_{2}(\mathrm{~b})$ in $\mathrm{AlOOH}$, structural models of these species were constructed for goethite from the known X-ray structure. The estimated isotopic compositions of the $\mathrm{CO}_{2}(\mathrm{a})$ and $\mathrm{CO}_{2}(\mathrm{~b})$ species differed dramatically from each other in both $\mathrm{AlOOH}$ and $\mathrm{FeOOH}$. For $\mathrm{FeOOH}$, according to the quantum mechanical calculations, the open channel site $\mathrm{CO}_{2}(\mathrm{a})$ should harbor a highly isotopically light population of carbon atoms, depleted in ${ }^{13} \mathrm{C}$ by nearly $2 \%$ relative to $\mathrm{CO}_{2}(\mathrm{~g})$, whereas the $\mathrm{CO}_{2}(\mathrm{~b})$ site was predicted to have an isotopic composition similar to that of $\mathrm{CO}_{2}(\mathrm{~g})$. One way to interpret the results of the calculations would be to infer that most of the $\mathrm{CO}_{2}(\mathrm{~m})$ was in the form of $\mathrm{CO}_{2}(\mathrm{a})$. This is supported by the lower energy of the $\mathrm{CO}_{2}(\mathrm{~b})$ configuration relative to $\mathrm{CO}_{2}(\mathrm{a})$ in diaspore (the energy difference for goethite could not be estimated from the calculations).

On the other hand, given the accessibility of the open channels, it is difficult to believe that the speciation of $\mathrm{CO}_{2}(\mathrm{~m})$ in the solid does not end up being heterogeneous, with both types of defects being represented, and possibly more, given that some configurations would probably be missed in the $a b$ initio molecular dynamics conformer searching procedure. Furthermore, the 
relative energies of the two structures may not be the same in $\mathrm{FeOOH}$ as in $\mathrm{AlOOH}$. If some of the $\mathrm{CO}_{2}(\mathrm{~m})$ sites were structurally located within the open channels, the mineral could have a highly ${ }^{13} \mathrm{C}$-depleted isotopic signature relative to $\mathrm{CO}_{2}(\mathrm{~g})$. The predicted compositional contrast is almost great enough that the isotopic composition of $\mathrm{CO}_{2}$ (a) species could be mistaken for organic carbon. A depth-dependent variation in the fraction of $\mathrm{CO}_{2}(\mathrm{a})$ and $\mathrm{CO}_{2}(\mathrm{~b})$ could have a strong effect on the carbon isotope compositions of goethite crystals as a function of depth, interfering with the recording of the primary microbial-atmospheric profile.

\section{Final Remarks}

These examples, dealing with the history of the $\mathrm{PCO}_{2}$ of the Earth's atmosphere, one of the most pressing scientific problems of our time, show why geology must become focused more strongly at the molecular level. Exploration of the molecular-level details of the record of isotopes preserved in minerals and, ultimately, being able to sample isotope distributions at a site-specific level will require application of the best experimental and computational tools available. Moreover, it seems almost inevitable that solution of the energy problem must ultimately come from discovering effective ways to chemically trap solar energy on a large scale (80). Such traps must be made from geologically common materials because of the diffuse nature of the solar energy source, and their successful design will require a molecular-level understanding of these geological materials. Thus, there is no shortage of urgent, high-stakes geological problems. Paradoxically, priorities in geology remain focused on fieldwork, much like our sister science of biology was 100 years ago when geologists and biologists collaborated on the beginnings of structural investigations of hemoglobin (4). This focus must change as the plate-tectonic revolution fades into the annals of the history of science, and we anticipate a new century of geological discoveries.

\section{REFERENCES}

1. Alley, R. B. The Two Mile Time Machine Princeton University Press: Princeton, 2000.

2. Royer, D. L.; Berner, R. A.; Montañez, I. P.; Tabor, N. J.; and Beerling, D. J. GSA Today 2004, 14, 4. 
3. Gibbs, G. V. Am. Mineral. 1982, 67, 421.

4. Reichert, E. T.; Brown, A. P. The Crystallography of Hemoglobin. Carnegie Institute of Washington, Publication No. 116, 1909

5. Catlow C. R. A.; Thomas J. M.; Parker S. C.; Jefferson D. A. Nature, 1982, 295, 658 .

6. Car, R.; Parrinello, M. Phys. Rev. Lett. 1985, 55, 2471.

7 Chandler, D. Nature 2002, 417, 491.

8. Stillinger, F. H.; David, C. W. J. Chem. Phys.1978, 69, 1473.

9. Halley, J. W.; Rustad, J. R.; Rahman A. J. Chem. Phys. 1993, 98, 4110.

10 Mortier, W. J.; Van Genechten, K.; Gasteiger, J. J. Am. Chem. Soc.1985, 107, 829.

11. Aguado, A.; Bernasconi, L.; Jahn, S.; Madden, P. A. Faraday Discuss. 2003, $124,171$.

12. Soper, A. K.; Phillips, M. G. Chem. Phys. 1986, 107, 47

13. Silvestrelli, P. L.; Parrinello, M. Phys. Rev. Lett. 1999, 82, 5415.

14. Tuckerman, M. E.; Laasonen, K.; Sprik, M.; Parrinello, M. J. Chem. Phys. 1995, 103, 150.

15. Curtiss, L. A.; Halley, J. W.; Hautman, J.; Rahman, A.J. Chem. Phys. 1987, 86, 2319.

16. Villa, E. M.; Ohlin, C. A.; Rustad, J. R.; Casey, W. H. J. Am. Chem. Soc. 2009, 131, 16488.

17. Baes, C. F.; Mesmer, R. E. The Hydrolysis of Cations; Wiley: New York, 1976.

18. Rustad, J. R.; Dixon, D. A., Rosso, K. M.; and Felmy, A. R. J. Am. Chem. Soc. 1999, 121, 3234.

19. Martin, R. L.; Hay, P. J.; Pratt, L. R. J. Chem. Phys. A, 1998, 102, 3565.

20. Rustad, J. R.; Casey, W. H. Theor. Chem. Acc. 2006, 115, 136.

21. Banyai I.; Glaser J.; Read M. C.; Sandstrom M. Inorg. Chem. 1995, 34, 2423.

22. Silverman, J.; Dodson, R. W. J. Phys. Chem. 1952, 56, 846.

23. Rustad, J. R.; Felmy, A. R.; Rosso, K. M. J. Chem. Phys. 2004, 120, 7607.

24. Kuharski R. A.; Bader, J. S.; Chandler, D.; Sprik M.; Klein, M. L.; Impey, R. W. J. Chem. Phys. 1988, 89, 3248.

25. Huang, J. K.; Warshel, A. J. Am. Chem. Soc. 1987, 109, 715.

26. Parks, G. A.; de Bruyn, P. L. J. Phys. Chem. 1962, 66, 967.

27. Hiemstra, T.; Van Reimsdijk, W. H.; Bolt, G. H. J. Colloid. Interface Sci. 1989, 133, 91.

28. Rustad, J. R.; Dixon, D. A.; Felmy A. R. Geochim. Cosmochim. Acta. 2000, $64,1675$.

29. Rustad, J. R.; Felmy A. R.; and Hay, B. P. Geochim. Cosmochim. Acta. 1996, 60, 1553.

30. Russel, J. D.; Parfitt, R. L.; Fraser, A. R.; Farmer, V. C. Nature, 1974, 248, 220.

31. Rochester, C. H.; Topham, S. A. J. Chem. Soc. Faraday Trans. 1979, 75, 591.

32. Rustad, J. R.; Boily, J. F. Am. Mineral. 2010, 95, 414.

33. Catalano, J. G.; Fenter, P.; Park, C. Geochim. Cosmochim. Acta. 2009, 73, 2242.

34. Boily, J. F.; Felmy, A. R. Geochim. Cosmochim. Acta. 2008, 72, 3338.

35. Kowalksi, P. M.; Meyer, B.; Marx, D. Phys. Rev. B 2009, 79, art. no 115410.

36. Casey, W. H. Chem. Rev. 2006, 106, 1.

37. Rowsell, J.; Nazar, L. J. Am. Chem. Soc. 2000, 122, 3777.

38. Allouche, L.; Gerardin, C.; Loiseau, T., Taullele, F. Angew. Chem. Int. $\mathbf{2 0 0 0 , 3 9 , 5 1 1 . ~}$ 
39. Casey, W. H.; Rustad, J. R.; Banerjee, D.; Furrer, G. J. Nanopart. Res. 2005, 7, 377.

40. Rustad, J. R. and Felmy, A. R. Geochim. Cosmochim. Acta.2005, 69, 1405.

41. Feynman, R. P. Leighton R. B. and Sands M.The Feynman Lectures on Physics vol II, Addison-Wesley: Reading, MA

42. Boily, J. F. Colloids and Surfaces. Phys. Eng. Aspects 2001, 179, 11.

43. Venema P. Charging and ion adsorption behaviour of different iron (hydr) oxides PhD. Thesis, Wageningen Agricultural University: Wageningen, The Netherlands.

44. Wang, J. W.; Rustad J. R.; Casey, W. H. Inorg. Chem. 2007, 46, 2962.

45. Weidler, P. G.; Hug, S. J., Wetche, T. P.; Hiemstra, T. Geochim. Cosmochim. Acta. 1998, 62, 3407.

46. Langford, C. H.; Gray, H. B. Ligand Substitution Processes; W. A. Benjamin: New York, 1966.

47. Cygan, R. T.; Liang, J. J.; Kalinichev, A. J. Phys. Chem. B 2004, 108, 1255.

48. Chandler, D. Introduction to Modern Statistical Mechanics Oxford University Press: Oxford, 1987.

49. Bennett, C. H., Exact Defect Calculations in Model Substances, In: "Diffusion in Solids: Recent Developments"; Eds. Nowick, A. S.; Burton, J. J.; Academic Press, New York, 1975 p. 73.

50. Rustad, J. R.; Stack, A. G. J. Am. Chem. Soc. 2006 , 128, 14778.

51. Rustad, J. R.; Loring, J. S.; Casey, W. H. Geochim. Cosmochim. Acta. 2004, $68,3011$.

52. Loring, J. S.; Yu, P.; Phillips, B. L.; Casey W. H. Geochim. Cosmochim. Acta. 2004, 68, 2791

53. Villa, E. M.; Ohlin, C. A.; Balogh, E.; Anderson, T. M.; Nyman, M. D.; Casey, W. H. Am. J. Sci. 2008, 308, 942.

54. Dunitz, J. D.; Orgel, L. E. Adv. Inorg. Chem. 1960, $2,1$.

55. Klamt A.; Schuurmann, G. J. Chem. Soc. Perkin Trans. 1993, 2, 799.

56. Hemming, N. G.; Hanson, G. N. Geochim. Cosmochim. Acta. 1992, 56, 537.

57. Kotaka, M.; Kakihana, H. Nucl. Reactors 1977, 2, 1-12.

58. Oi, T. J. Nucl. Sci. Technol. 2000, 37, 166.

59. Oi T.; Yanase S. J. Nuc. Sci. Tech. 2001, 38, 429.

60. Zeebe, R. E. Geochim. Cosmochim. Acta. 2005, $692753-2766$.

61. Liu, Y.; Tossell J. A. Geochim. Cosmochim. Acta. 2005, 69, 3995.

62. Klochko, K.; Kaufman, A. J.; Yao, W. S.; Byrne, R. H.; Tossell, J. A. Earth and Planet. Sci. Lett. 2006, 248-276.

63. Rustad, J. R.; Bylaska E. J. J. Am. Chem. Soc. 2007, 129, 2222.

64. Pagani, M.; Lemarchand, D.; Spivack, A.; Gaillardet, J. Geochim. Cosmochim. Acta. 2005, 69, 953-961.

65. Hönisch, B.; Hemming, N. G.; Loose, B. Geochim. Cosmochim. Acta. 2007, 71, 1636.

66. Pagani, M.; Spivack, A. Geochim. Cosmochim. Acta. 2007, 71, 1642.

67. Sen, S.; Stebbins, J. F.; Hemming N. G.; Ghosh, B. Am. Mineral. 1994, 79, 819.

68. Lemarchand, D.; Wasserburg, G. T.; Papanastassiou, D. A. Geochim. Cosmochim. Acta. 2004, 68, 4665

69. Fantle, M; DePaolo, D. J. Geochim. Cosmochim. Acta. 2007, 71, 2524.

70. Cerling T. E. Am. J. Sci. 1991, 291, 377.

71. Yapp, C. J.; Poths H. Nature 1992, 355, 342.

72. Nier, A. O.; Gulbransen, E. A. J. Am. Chem. Soc. 1939, 61, 697.

73. Galimov, E. M. The Biological Fractionation of Isotopes. Academic Press, New York, 1985. 